Discussion

Papers

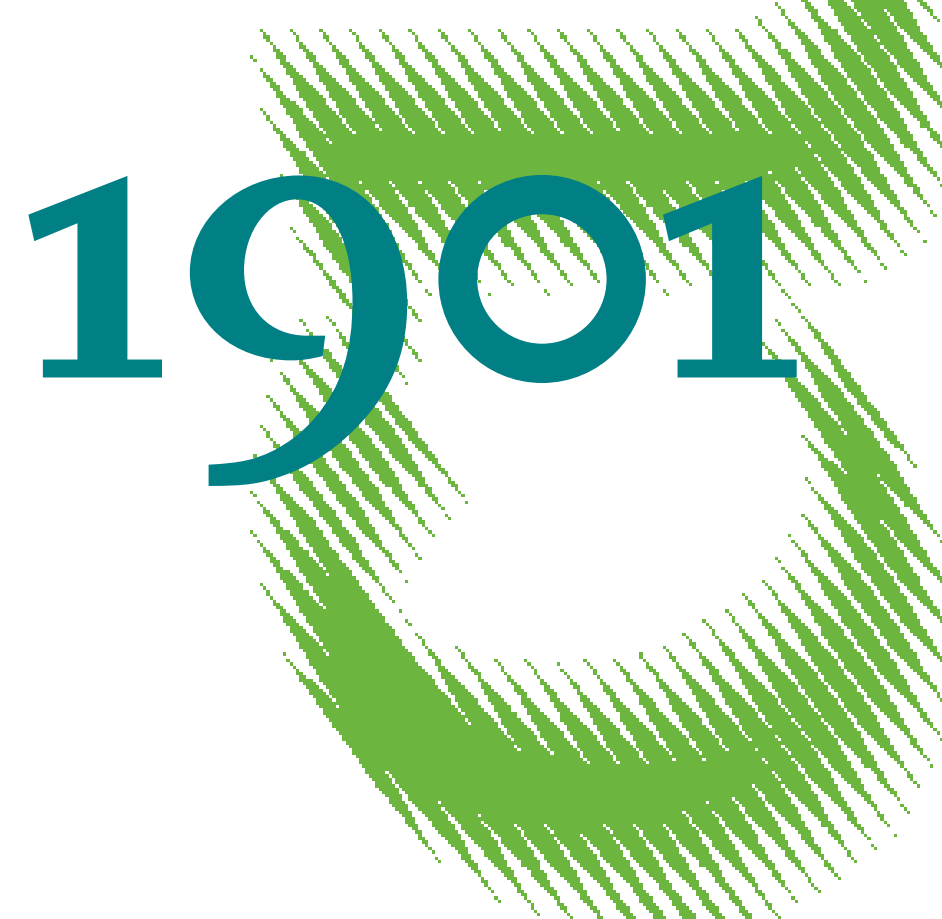

Government Spending Multipliers in (Un)certain Times 
Opinions expressed in this paper are those of the author(s) and do not necessarily reflect views of the institute.

IMPRESSUM

(C) DIW Berlin, 2020

DIW Berlin

German Institute for Economic Research

Mohrenstr. 58

10117 Berlin

Tel. +49 (30) $89789-0$

Fax +49 (30) $89789-200$

http://www.diw.de

ISSN electronic edition 1619-4535

Papers can be downloaded free of charge from the DIW Berlin website:

http://www.diw.de/discussionpapers

Discussion Papers of DIW Berlin are indexed in RePEc and SSRN:

http://ideas.repec.org/s/diw/diwwpp.html

http://www.ssrn.com/link/DIW-Berlin-German-Inst-Econ-Res.html 


\title{
Government Spending Multipliers in (Un)certain Times*
}

\author{
Jan Philipp Fritsche ${ }^{\dagger}$, Mathias Klein ${ }^{\ddagger}$ and Malte Rieth ${ }^{\S}$
}

First version: February 5, 2018.

This version: September 15, 2020

\begin{abstract}
We estimate the dynamic effects of government spending shocks, using time-varying volatility in US data modeled through a Markov switching process. We find that the average government spending multiplier is significantly and persistently above one, driven by a crowding-in of private consumption and non-residential investment. We rationalize the results empirically through a contemporaneously countercyclical response of government spending and an efficient weighting of observations inversely to their error variance. We then show that the multiplier is significantly smaller when volatility is high, consistent with theories predicting reduced effectiveness of fiscal interventions in uncertain times.
\end{abstract}

Keywords: Fiscal policy, government spending multiplier, uncertainty, structural vector autoregressions, heteroskedasticity.

JEL classifications: C32, E62, H50.

\footnotetext{
* We thank Nadav Ben Zeev, Francesco Bianchi, Fabio Canova, Carlo Favero, Ethan Ilzetzki, Christophe Kamps, Helmut Lütkepohl, Morten Ravn, Nora Traum and participants of the CEF Milan, Verein für Socialpolitik, European Central Bank and DIW seminars for helpful comments and suggestions. The opinions expressed in this article are the sole responsibility of the authors and should not be interpreted as reflecting the views of Sveriges Riksbank.

$\dagger$ Humboldt Universität Berlin, e-mail: jfritsche@diw.de

$\ddagger$ Corresponding author, Sveriges Riksbank, Monetary Policy Department - Research, SE-103 37 Stockholm, Sweden, email: mathias.klein@riksbank.se

$\S$ DIW Berlin, e-mail: mrieth@diw.de
} 


\section{Introduction}

There is renewed interest among researchers and policy makers in the effects of fiscal policy on macroeconomic activity. This topic is important because central banks have lost their ability to stimulate the economy through reductions in the policy interest rate. Despite the importance, there is a wide range of different estimates for the size of the government spending multiplier; that is, by how much does aggregate output rise following an exogenous increase in government spending. In addition, there is a discussion whether the effectiveness of fiscal interventions depends on the state of the economy (Auerbach and Gorodnichenko, 2012; Ramey and Zubairy, 2018; Tagkalakis, 2008).

In this article, we use an agnostic identification approach to estimate the dynamic effects of government spending shocks in the United States. For identification we exploit time-variation in the volatility of US data, which we model through a Markov switching in heteroskedasticity process following Herwartz and Lütkepohl (2014). Several studies show that changes in volatility are a main feature of macroeconomic time series (Stock and Watson, 2002, Justiniano and Primiceri, 2008, Carriero et al., 2016, Diebold et al., 2017). We use these changes in volatility as a 'probabilistic instrument' (Rigobon, 2003) for government spending shocks to study how fiscal policy influences the macroeconomy.

Compared to other identification schemes frequently used in the fiscal policy literature, identification through heteroskedasticity offers three main advantages. First, unlike the recursive identification scheme (Blanchard and Perotti, 2002), it does not impose a timing restriction and allows for a contemporaneous response of government spending to output. Second, contrary to the narrative identification scheme (Barro and Redlick, 2011; Ramey, 2011), it does not require the availability of a valid external instrument for postWWII data. Third, different to linear models, it generalizes the estimation by weighting observations inversely to their sampling uncertainty, thereby increasing efficiency.

Furthermore, because the model is nonlinear, it allows for studying the state-dependent effects of government spending shocks across different volatility regimes. The theoretical analysis of Bloom (2009) and Bloom et al. (2018) predicts that fiscal policy is less effective when uncertainty, modeled through time-varying structural shock variances, is high, because firms then postpone hiring and capital decisions. Similarly, Bernanke (1983) and McDonald and Siegel (1986) show that higher uncertainty increases the real option value of waiting before making investment decisions. Additionally, in uncertain times there is a stronger precautionary savings motive by consumers (Fernandez-Villaverde et al., 2011, Basu and Bundick, 2017). By allowing the effects of government spending shocks to depend on the volatility regime, our model enables us to test whether these theoretical predictions are supported by the data.

We find that exogenous changes in government spending are, on average, an effective tool to stimulate the economy. A positive government spending shock leads to a significant 
increase in output and private consumption. The crowding-in of private consumption is driven by a persistent and significant rise in both non-durable and durable consumption. Moreover, the unexpected fiscal stimulus leads to a significantly rise in inflation, shortterm interest rates, employment, and hours worked.

We estimate a cumulative two-year government spending multiplier of 1.5. The multiplier is significantly larger than one for about two years. This estimate is in line with recent evidence (Ben Zeev and Pappa, 2017; Chodorow-Reich, 2019), but larger than estimates typically found when applying timing-restrictions or exogenous changes in defense spending. We show that there are three main reasons for the differences across identification schemes: two economic and one technical reason. First, we do not restrict the contemporaneous response of government spending to output to zero but estimate this elasticity. We document a significantly negative response. As the size of the government spending multiplier is negatively related to this elasticity, a countercyclical spending response implies a larger multiplier, as shown formally by Caldara and Kamps (2017). While their approach requires the availability of non-fiscal instruments to estimate the government spending-output elasticity, our methodology allows estimating this relationship by making use of a natural feature of macroeconomic time series, changes in volatility. Second, military spending shocks produce smaller government spending multipliers than general government spending shocks. Third, accounting for heteroskedasticity generalizes the estimation. It gives more weight to observations with low error variance compared to observations with high error variance. This increases efficiency and affects point estimates.

Regarding state-dependency, we find empirical evidence for the hypothesis that the impact of government spending shocks varies across volatility regimes. The multiplier is significantly larger in the low than in the high volatility state. This result is consistent with the theoretical predictions and it suggests that the level of uncertainty in the economy significantly influences the effectiveness of government spending policy. It adds to evidence highlighting that more disagreement amongst US professional forecasters about future government spending, or higher stock market volatility, reduces the impact of recursively identified fiscal spending innovations (Ricco et al., 2016, Alloza, 2017), and that higher macroeconomic uncertainty lowers the effectiveness of narratively identified tax shocks (Bertolotti and Marcellino, 2017). Moreover, it rationalizes our finding of an average multiplier above one as the generalized model attaches larger weight to the more precisely estimated larger multiplier of the low volatility regime.

This paper is closely related to two studies that also use changes in volatility to identify fiscal policy shocks. Bouakez et al. (2014) model conditional heteroskedasticity through a GARCH process, whereas we use a Markov switching framework. Lütkepohl and Schlaak (2018) show that the latter is usually the better choice when the data generating process is unknown because modeling time-varying volatility through a latent variable gives more voice to the data, yielding more precise estimates of the structural parameters. 
Moreover, Bouakez et al. (2014) pre-define one break point in 1979 for general, unspecified changes in the effects of fiscal policy. Instead, our state-dependent approach is agnostic about the change points, which can be multiple and are determined endogenously, and, at the same time, more specific about the nonlinearities, which are due to changes in uncertainty. Lewis (2019) concentrates on the econometric theory of identification through heteroskedasticity. He presents the methodology in an extensive and rigorous manner and then applies it to fiscal policy. We depart in three dimensions, which are important from a policy perspective. First, while that paper focuses on estimating aggregate fiscal multipliers, we study the transmission mechanism in detail, investigating how the private sector responds to government spending shocks. Second, we provide an empirical account and, thereby, rationalization of what drives the differences in estimated multipliers in the literature. Third, we extend the methodology to a state-dependent setting and indeed find that the government spending multiplier is significantly lower when uncertainty is high, that is, when fiscal stimulus is probably needed most.

The rest of the paper is structured as follows. Section 2 describes the methodology and data. Section 3 presents our baseline results and shows robustness of the estimated average multiplier. In Section 4, we discuss our findings in the light of the literature. In Section 5, we allow for state-dependent effects of government spending shocks and investigate how uncertainty regimes affect the fiscal transmission mechanism. Finally, Section 6 concludes.

\section{Empirical methodology and data}

In this section, we first present the empirical model and the identification strategy. We then describe the data and the estimation procedure.

\subsection{The MS-SVAR model}

The general $M$ state, $p$ lag reduced form Markov switching in heteroskedasticity structural vector autoregressive (MS-SVAR) model with $n$ variables is

$$
y_{t}=c+A_{1} y_{t-1}+\cdots+A_{p} y_{t-p}+u_{t} .
$$

In the baseline model $y_{t}=\left[g_{t}, x_{t}, r_{t}\right]^{\prime}$, with $g_{t}$ government spending, $x_{t}$ output, and $r_{t}$ the three-month Treasury Bill rate. Further, $c$ is a vector of constants, $A_{i}$ are parameter matrices with $i=1, \ldots, p$, and $u_{t}$ is a vector of zero-mean reduced form errors. In standard SVAR models, a linear transformation is used to obtain the structural shocks,

$\epsilon_{t}$, as $\epsilon_{t}=B^{-1} u_{t}$ or $B \epsilon_{t}=u_{t}$. Usually, $\epsilon_{t} \sim\left(0, I_{n}\right)$ and the reduced form covariance matrix is decomposed as $\mathbb{E}\left[u_{t} u_{t}^{\prime}\right]=\Sigma_{u}=B B^{\prime}$. 
In our analysis, we follow Herwartz and Lütkepohl (2014) and assume that $\mathbb{E}\left[u_{t} u_{t}^{\prime}\right]=$ $\Sigma_{u}\left(S_{t}\right) . S_{t}$ is a first order discrete valued Markov process that can take on $M$ different values, $S_{t}=1, \ldots, M$, with transition probabilities given by $p_{k l}=P\left(S_{t}=l \mid S_{t-1}=\right.$ $k), k, l=1, \ldots, M$. For estimation with maximum likelihood (ML), we assume that $u_{t}$ is normally and independently distributed conditional on a given state:

$$
u_{t} \mid S_{t} \sim \operatorname{NID}\left(0, \Sigma_{u}\left(S_{t}\right)\right)
$$

The normality assumption is not critical for the empirical analysis. If conditional normality is not fulfilled, then the estimation will simply be pseudo ML.

While the model is linear in a given state, it is nonlinear as a whole. Equations (1) and (2) imply that only the reduced form covariance matrix switches between states, as we are interested in the heteroskedasticity features of the data for identification purposes. Thus, we impose more regularity on the model than in the MS-SVAR model used by Sims and Zha (2006). Furthermore, although there is a finite number of states in practice, the model captures smooth transitions between them as the actual volatility is described as a mixture of states, each weighted with a certain probability that may be less than one.

We exploit these changes in the covariance matrix for the identification of structural shocks that are consistent with the statistical properties of the data. We consider two states of the world - a high-volatility state and a low-volatility state. Then, we can decompose the reduced form covariance matrices as:

$$
\Sigma_{u}(1)=B B^{\prime} \quad \text { and } \quad \Sigma_{u}(2)=B \Lambda_{2} B^{\prime}
$$

The main idea underlying this identification strategy is to use additional moments from the data to ensure that the order condition holds. With only one state-independent estimate of $\Sigma_{u}$, we would have only six estimable moments for $n=3$ but nine unknown parameters in $B$, if the latter is unrestricted. With two volatility regimes, we have 12 moments and 12 unknowns as $\Lambda_{2}=\operatorname{diag}\left(\lambda_{21}, \lambda_{22}, \lambda_{23}\right)$ contains only three additional (positive) elements on the main diagonal and otherwise zeros. Lanne et al. (2010) show that if these elements are all distinct, the rank condition holds, that is, the decomposition in (3) is unique apart from changes in the signs of the shocks and permutations of the $\lambda_{2 n}$ and corresponding orderings of the columns of $B$. In summary, if we order the $\lambda_{2 n}$, assume that the structural shocks are orthogonal, have the same impact effects across states, and are normalized to have unit variance in the first state, we can uniquely identify the structural shocks through the linear transformation $\epsilon_{t}=B^{-1} u_{t}$.

The crucial assumption for point-identification of the full $B$-matrix is that the $\lambda_{2 n}$ are all different. As they can be interpreted as variance shifts of the structural shocks relative to the benchmark state (in our case the low-volatility state), having distinct $\lambda_{2 n}$ means that the volatility shifts are not the same for all shocks. This assumption can be 
checked after estimation, which is an advantage over more conventional just-identifying assumption that cannot be assessed. Furthermore, zero restrictions on $B$ can become over-identifying in the presence of heteroskedasticity and, hence, testable. Finally, for the specific decomposition (3), we assume that $B$ is state-independent. We relax this assumption in Section 5.

Figure 1 illustrates how identification through heteroskedasticity works. Both panels present artificial data describing the relationship between government spending and output under the assumption that government spending negatively depends on output (government spending is countercyclical) and output increases with government spending (government spending multiplier is positive). It is impossible to identify the output response to variations in government spending from the left panel alone, because every line fitted to the system will match the data equally badly. However, once the variance of the spending shock increases, as shown in the right panel, shifts of the spending equation increase relative to shifts of the output equation. The circle turns into an ellipse that is centered around the output equation such that the latter can be estimated from the data. The important condition is that there are no proportional variance changes as this would simply imply a widening of the circle. To additionally estimate the spending response, both states are needed. More generally, if there are distinct relative variance shifts of the structural shocks, the full impact matrix can be point-identified.

Figure 1: Graphical illustration of identification through heteroskedasticity. Notes: Left panel shows state 1 . the right panel state 2 .
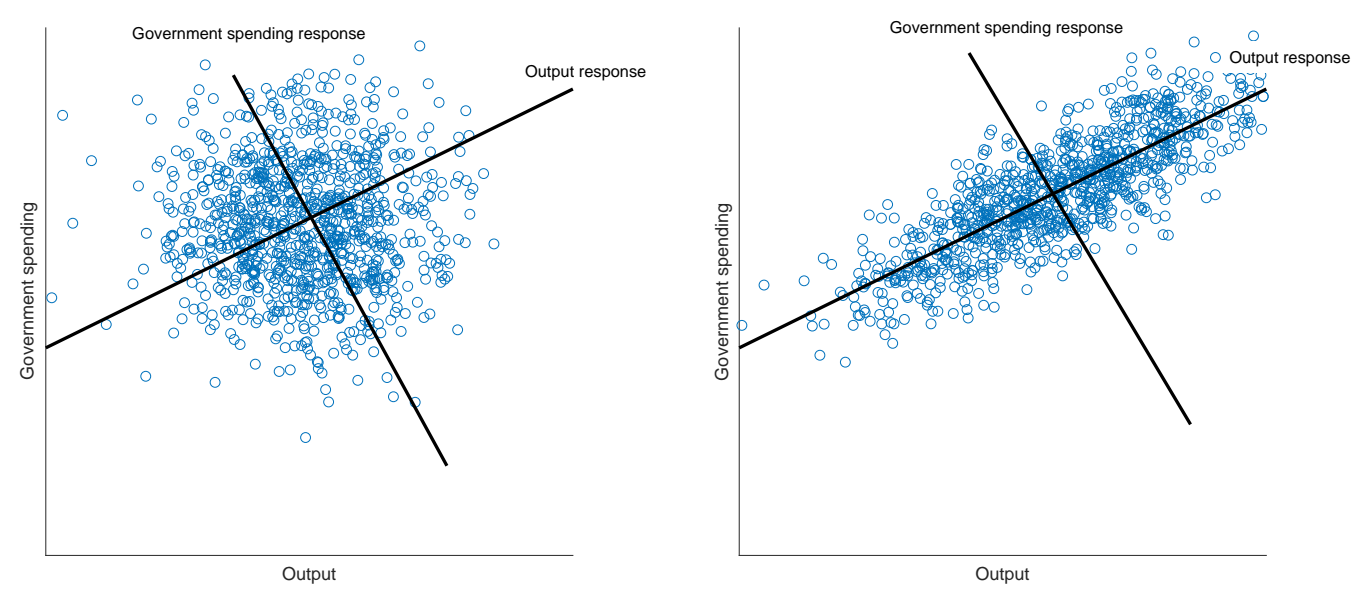

Relying on this identification approach is also convincing from an economic point of view. Several studies document that changes in volatility are a main feature of macroeconomic data (Stock and Watson, 2002, Justiniano and Primiceri, 2008, Carriero et al., 2016, Diebold et al., 2017). One prominent example is the change associated with the Great Moderation that started around the 1980s. Macroeconomic aggregates are more volatile before and fluctuate less during that period. Our approach makes use of such 
data features to identify structural shocks. This is less restrictive than using timing, sign, or external instrument restrictions. It does not restrict the size or the sign of the impact, nor does it require the availability of a valid instrument for post-WWII data.

\subsection{Estimation, data, and model selection}

We estimate the parameters in (1) by means of the expectation maximization (EM) algorithm developed for structural models by Herwartz and Lütkepohl (2014). Crucial for the analysis is to incorporate the regime-switching nature of the covariance matrix described in (2), given the restrictions in (3). We use the following concentrated out log likelihood function in the maximization step of the EM algorithm, which weighs observations according to their sampling uncertainty:

$$
\mathcal{L}\left(B, \Lambda_{m}\right)=\frac{1}{2} \sum_{m=1}^{M}\left[\widehat{T}_{m} \log \left(\operatorname{det}\left(\Sigma_{u}(m)\right)\right)+\operatorname{tr}\left(\left(\Sigma_{u}(m)\right)^{-1} \sum_{t=1}^{T} \widehat{\xi}_{m t \mid T} \widehat{u}_{t} \widehat{u}_{t}^{\prime}\right)\right]
$$

where $\xi_{m t \mid T}, m=1, \ldots, M, t=1, \ldots, T$ are the model smoothed probabilities, $T_{m}=$ $\sum_{t=1}^{T} \xi_{m t \mid T}$, and the hat denotes estimated parameters from the previous iteration.

Once the EM algorithm converges, we obtain standard errors of the point estimates of the parameters through the inverse of the negative Hessian matrix evaluated at the optimum. We use them as a statistic to determine whether the estimated variances change significantly and by differing amounts across states. This is a requirement for identification. For the dynamic analysis, we compute bootstrapped impulse responses, following Herwartz and Lütkepohl (2014). Given the heteroskedasticity, classical residual bootstrapping may be problematic for generating reliable confidence intervals. Re-sampling needs to preserve the second order characteristics of the data. Therefore, we use a fixed design wild bootstrap with $u_{t}^{\star}=\varphi_{t} \widehat{u}_{t}$, where $\varphi_{t}$ is a random variable independent of $y_{t}$ following a Rademacher distribution. $\varphi_{t}$ is either 1 or -1 with probability 0.5 .

Our baseline model consists of three endogenous variables, namely government spending (the sum of government consumption and government investment), GDP, and the three-month Treasury Bill rate. Several studies show that the conduct of monetary policy influences the macroeconomic effects of fiscal policy (Canova and Pappa, 2011; Davig and Leeper, 2011). Specifically, the extent to which monetary policy reacts to the consequences of fiscal spending shocks is an important determinant of their size. Therefore, in any study of the effects of government spending shocks, it is important to explicitly control for the stance of monetary policy which we do by including a short term interest rate in the vector of endogenous variables. In a latter section, we show that our main qualitative results are robust when controlling tax policy, fiscal foresight and when excluding the period during which the interest rate has reached its lower bound. All series are from Ramey and Zubairy (2018). Nominal government spending and output are both 
divided by potential output such that they are measured in dollar equivalents. The baseline sample covers the period 1954Q1-2015Q4. The starting date avoids the years from 1945 to the Korean war, commonly considered to be special within post-WWII data from a fiscal point of view (Monacelli et al., 2010). We use five lags to account for potential seasonal patterns in the quarterly variables. This also increases the confidence in results for longer impulse response horizons. ${ }^{1}$

Table 1: Model selection. Notes: $L_{T}$ denotes the likelihood function evaluated at the optimum, $A I C=-2 \log \left(L_{T}\right)+2 f$, and $S C=-2 \log \left(L_{T}\right)+\log (T) f$, with $f$ the number of free parameters.

\begin{tabular}{lccc}
\hline Model & $\log \left(L_{T}\right)$ & $\mathrm{SC}$ & $\mathrm{AIC}$ \\
\hline Reduced form linear VAR(5) & 1791.8 & -3335.5 & -3493.6 \\
Reduced form MS(2)-VAR(5) & 1899.8 & -3459.1 & -3675.7 \\
\hline
\end{tabular}

Table 1 shows some specification statistics for the two-state Markov switching model. It is clearly preferred over a standard linear VAR according to the log-likelihoods and both types of information criteria. The latter is shown to work well to judge the performance of MS models (Psaradakis and Spagnolo, 2006), whereas standard tests are problematic for this purpose as some parameters might not be identified under the null hypothesis of a smaller number of states than under the alternative (Hansen, 1992). The evidence against the linear model is strong. This suggests notable changes in volatility in the sample and that the identification of the structural shocks can be achieved by relying on the heteroskedasticity property of the data.

\section{Government spending shocks and multipliers}

\subsection{Estimated volatility regimes and identification}

We first analyze the estimated state-dependent reduced form covariances to see whether the model captures and separates the changes in volatility apparent in the data, according to Table 1, which are crucial for our identification strategy. This information also helps us interpret our endogenously identified regimes. Table 2 presents the estimated state covariances of the MS(2)-SVAR(5) model. It shows strong increases in volatility in state 2. The variances of the reduced form errors in the equations for public spending, output, and the interest rate increase by factors of 3,5 , and 17 , respectively. We read this as further evidence that the sample is characterized by strong changes in volatility.

The table also shows that the covariances increase substantially (in absolute value) in state 2 ; by about similar multiples as the variances relative to state 1 . These changes in the covariances illustrate the idea behind identification through heteroskedasticity. In a

\footnotetext{
${ }^{1}$ All our qualitative results are robust when adjusting the lag length.
} 
Table 2: Estimated state covariances of $\operatorname{MS}(2)-\operatorname{SVAR}(5)$ model with $y_{t}=\left[g_{t}, x_{t}, r_{t}\right]^{\prime}$.

\begin{tabular}{lcc}
\hline State $1: \Sigma_{u}(1)$ & State $2: \Sigma_{u}(2)$ \\
\hline$\left[\begin{array}{lll}0.024 & \cdot & \cdot \\
0.033 & 0.228 & \cdot \\
0.001 & 0.028 & 0.062\end{array}\right]$ & {$\left[\begin{array}{ccc}0.079 & . & \cdot \\
0.073 & 1.164 & \cdot \\
-0.016 & 0.280 & 1.055\end{array}\right]$} \\
\hline
\end{tabular}

period of high government spending volatility, we learn more about the relation between government spending and output as the covariance between both variables temporarily increases. Government spending shocks are then more likely to occur and can be used as a 'probabilistic instrument' (Rigobon, 2003) to trace out the response of output.

To achieve identification from a statistical point of view, we need significant and differential changes in the volatility of the structural shocks. Table 3 shows the estimated structural variances in state 2 . As the ordering of the $\lambda_{2 n}$ is arbitrary, we simply order them from smallest to largest. All estimates are significantly larger than one, implying that all structural shock variances increase when switching from state 1 to state 2 . Thus, we label state 2 the high volatility state. Identification requires that the variance shifts are all distinct from each other. This is the case according to their standard errors, which do not overlap, and suggests that the decomposition in (3) is unique. ${ }^{2}$

Table 3: Estimates and standard errors of relative variances of the MS(2)-SVAR(5) model. Note: The standard errors are obtained from the inverse of the negative Hessian evaluated at the optimum.

\begin{tabular}{ccc}
\hline Parameter & Estimate & Standard error \\
\hline$\lambda_{21}$ & 3.25 & 0.89 \\
$\lambda_{22}$ & 6.05 & 1.38 \\
$\lambda_{23}$ & 17.28 & 3.75 \\
\hline
\end{tabular}

Figure 2 presents the estimated smoothed state probabilities to develop a notion about the economic drivers of the regimes. The upper part shows the smoothed probabilities for the high volatility regime. The high volatility regime prevails in the first part of the sample, the low-volatility state dominates the second part. This general pattern might reflect the changes associated to the relatively tranquil times of the Great Moderation in the 1990s and 2000s with high growth and low inflation. In addition, many of the transitions to the high volatility state are associated with specific events in the economic history of the US. There are peaks around the OPEC oil prices shocks in the late 1960s and the beginning of the 1970s. Moreover, there is a spike around the Energy Crisis,

\footnotetext{
2 This is not a formal test. Such a test does not exist for the Markov switching in heteroskedasticity model that we use, as the asymptotic distributions of standard tests are unknown under the null hypothesis of no identification. Lütkepohl et al. (2018) propose a formal identification test for a model with two known and non-recurring volatility regimes. They provide evidence that the test leads to similar conclusions as assessing the standard errors of the $\lambda_{2} n$.
} 
the subsequent economic recession, as well as the chairmanship of the Federal Reserve of Paul Volcker at the end of the 1970s and the first half of the 1980s. In the second part of the sample, there are peaks around the burst of the Dot-com Bubble in 2001 and the Great Recession in 2009. Overall, this short narrative suggests that the endogenously determined regimes capture relevant developments in the US.

Figure 2: Smoothed state probabilities. Notes: The figure shows the smoothed state probabilities $\hat{\xi}_{m t \mid T}$ for the high volatility state $(m=2)$ in the upper panel and recessions defined by the NBER in the lower panel.
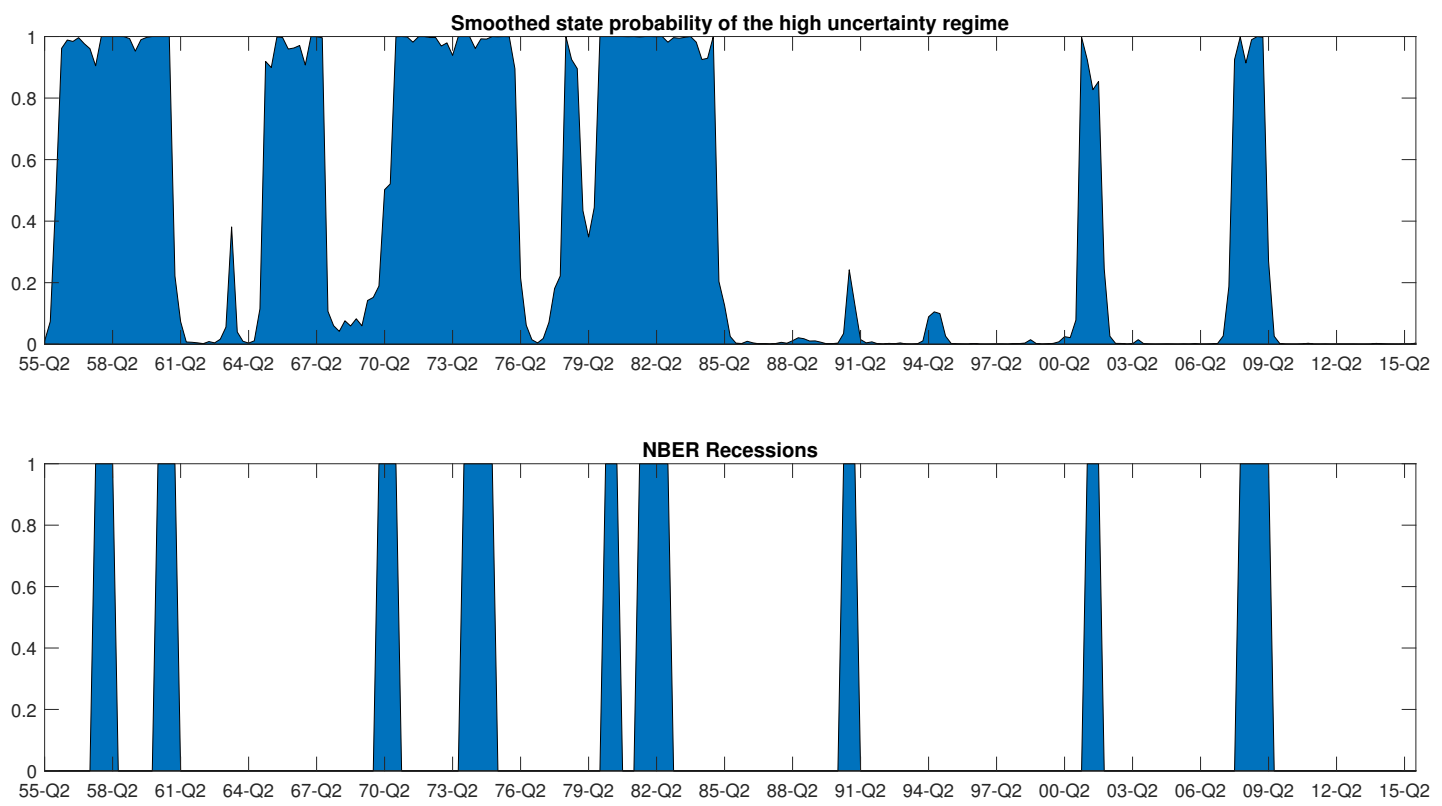

The estimated probabilities and shock variances can also be rationalized from a fiscal policy perspective. As shown by Davig and Leeper (2011), fiscal policy during the pre-Volcker period is characterized by a high degree of instability. In particular, they find that during that period, fiscal policy deviated substantially from a policy rule that induces government debt sustainability. This fiscal instability can affect private agents' consumption and investment decision as it complicates the projection of future policy adjustments. Consequently, an unstable fiscal policy environment might increase economic uncertainty reflected in larger fluctuations of aggregate variables. Moreover, other studies detect a change in the fiscal transmission mechanism at the beginning of the 1980s (Bilbiie et al., 2008; Perotti, 2005) which, in light of our smoothed probabilities, seems to be associated with moving from the mainly high uncertainty regime to the mainly low uncertainty regime. Besides the specific conduct of fiscal policy, the smoothed probabilities spike around specific war episodes in the US history, such as the Lebanon Crisis, the Vietnam War, and the Afghanistan War. Because military spending is one main part of overall government spending, substantial increases in defense spending induced by military interventions lead to larger movements in government spending, which finally implies more volatility in public expenditures. 
The bottom panel shows recessions, as defined by the NBER. It highlights that state 2 has some commonalities with recessions but measures something different. The correlation between both series is 0.43 .

Having labeled the regimes, we now turn to the interpretation of the structural shocks. As mentioned above, our data-driven identification scheme is not based on a priori economic reasoning about the model-economy and a corresponding ordering of the columns of $B$ or the respective $\lambda_{2 n}$. Thus, to attach an economic label to the statistically identified shocks, we inspect the forecast error variance decomposition and call the shock that explains the largest part of the variance in government spending a government spending shock. This idea is based on the identification scheme of Blanchard and Perotti (2002), which implies that government spending is contemporaneously exclusively driven by public spending shocks. We relax this assumption and allow for the possibility that other shocks affect government spending as well instantaneously, but we maintain the presumption that government spending shocks are the main driver at the quarterly frequency.

Table 4: Forecast error variance decompositions.

\begin{tabular}{llcccccc}
\hline \multirow{2}{*}{ Horizon } & & \multicolumn{3}{c}{ Shock in state 1 } & \multicolumn{3}{c}{ Shock in state 2} \\
\multirow{3}{*}{ Variable } & $\epsilon_{t}^{g}$ & $\epsilon_{t}^{x}$ & $\epsilon_{t}^{r}$ & $\epsilon_{t}^{g}$ & $\epsilon_{t}^{x}$ & $\epsilon_{t}^{r}$ \\
\hline \multirow{3}{*}{4 quarter } & Spending & 0.96 & 0.04 & 0.00 & 0.93 & 0.07 & 0.00 \\
& GDP & 0.37 & 0.62 & 0.01 & 0.24 & 0.73 & 0.03 \\
& T-Bill rate & 0.01 & 0.02 & 0.98 & 0.00 & 0.01 & 0.99 \\
\hline \multirow{3}{*}{12 quarters } & Spending & 0.96 & 0.04 & 0.00 & 0.91 & 0.07 & 0.02 \\
& GDP & 0.38 & 0.61 & 0.01 & 0.24 & 0.73 & 0.03 \\
& T-Bill rate & 0.04 & 0.08 & 0.88 & 0.01 & 0.03 & 0.96 \\
\hline \multirow{3}{*}{20 quarters } & Spending & 0.97 & 0.03 & 0.01 & 0.92 & 0.05 & 0.03 \\
& GDP & 0.39 & 0.58 & 0.02 & 0.24 & 0.68 & 0.08 \\
& T-Bill rate & 0.07 & 0.20 & 0.73 & 0.02 & 0.09 & 0.90 \\
\hline & Spending & 0.98 & 0.02 & 0.00 & 0.95 & 0.03 & 0.02 \\
& GDP & 0.38 & 0.56 & 0.06 & 0.22 & 0.61 & 0.17 \\
& T-Bill rate & 0.11 & 0.23 & 0.66 & 0.03 & 0.10 & 0.87 \\
\hline
\end{tabular}

Table 4 shows the variance decompositions at various horizons and in both states. As before, shocks are ordered according to the size of their variances. Given our labeling scheme, there is little ambiguity in finding the structural government spending shock $\epsilon_{t}^{g}$. It is the first shock, which explains more than $95 \%$ of the variance of government spending at all horizons and in both states. This already indicates that our government spending shocks are similar to recursively identified ones, but not identical.

We confirm this impression in Figure 3, which compares the standardized government spending shocks to those of a linear model identified through a Cholesky decomposion with government spending ordered first. The correlation between both series is 0.85 , suggesting that the shocks are closely related but different. These differences will turn out to be important quantitatively, as we show below. The shocks from the linear model show 
a clear pattern of heteroskedasticity, being generally more volatile during the first part of the sample and fluctuating less in the second part. This coincides with the estimated volatility states in Figure 2, which are mostly in the high volatility regime before the mid-1980s. Thus, in contrast to the MS model, the linear model does not appropriately account for the volatility changes of the underlying data.

Figure 3: Comparison of government spending shocks. Notes: The figure shows the estimated government spending shocks from the unrestricted Markov switching model (solid line) and from a linear-recursive model (dashed line).

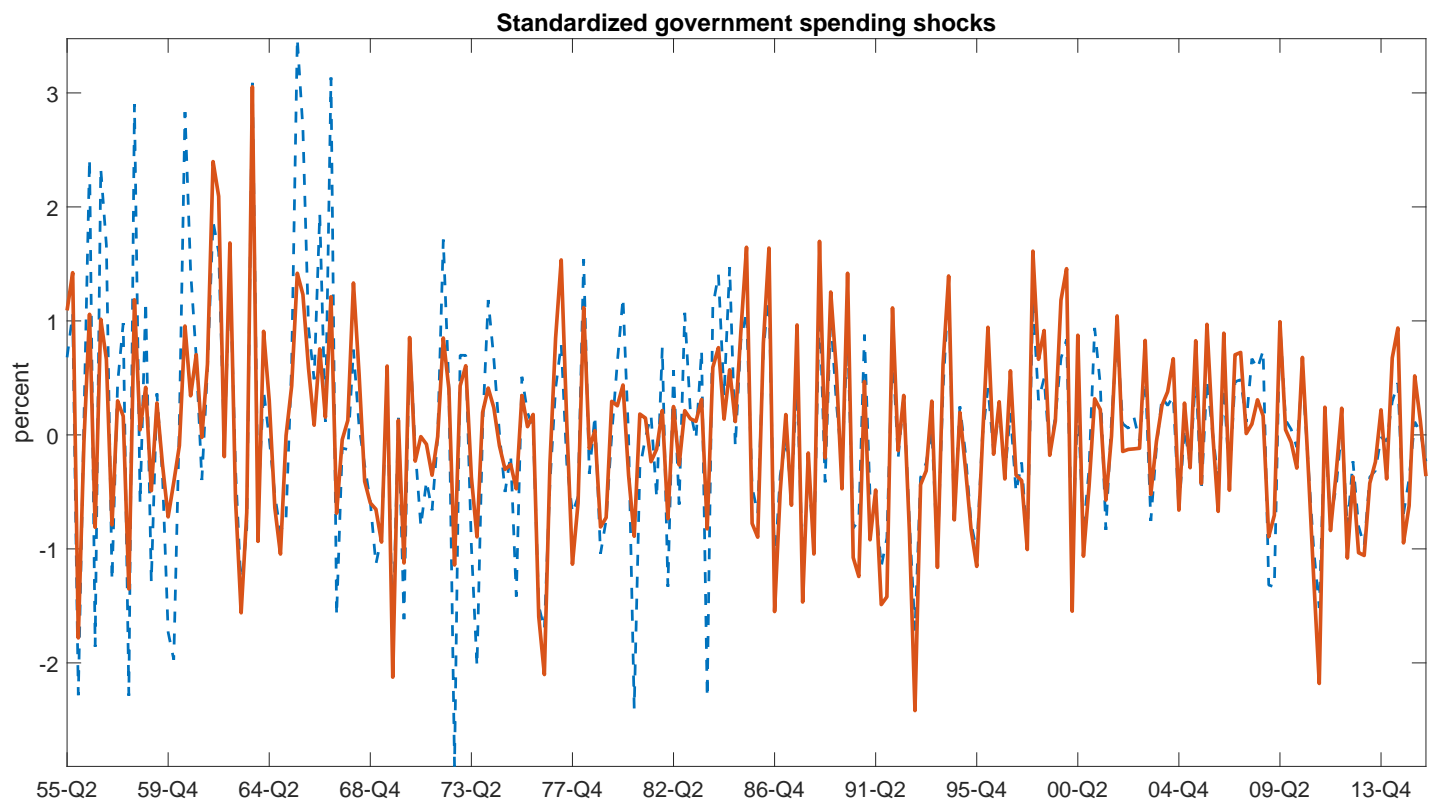

Finally, the other two shocks resemble an unspecified output shock and a interest rate shock. But the exact interpretation and labeling are of no specific interest for the following. The second shock explains more than half of the variation in output in both states and at all horizons. The third shock explains nearly all of the unpredictable changes in the T-Bill rate in the first year, and at least $66 \%$ after five years.

\subsection{Impulse responses for baseline model}

Figure 4 shows the impulse responses to all three shocks. ${ }^{3}$ The first column presents the effects of the government spending shock on the endogenous variables in rows. Shaded areas indicate $90 \%$ confidence bands. A shock of one standard deviation leads to a significant contemporaneous increase in government spending by about $0.15 \%$. The response is highly persistent, reaching a maximum after three years. ${ }^{4}$ The unexpected fiscal expansion has an immediate and substantial positive effect on output, which increases significantly by $0.3 \%$. GDP rises further for the first three quarters, before gradually returning to the

\footnotetext{
${ }^{3}$ The responses are calculated for the low volatility state. Because the estimated impact effects do not vary across states, the responses in the high volatility state are the same up to scaling.

${ }^{4}$ The spending responses converges back to steady state at longer horizons.
} 
level where it would have been without the shock. The T-Bill rate increases significantly upon impact as well and remains statistically different from zero for about one year. The expansionary effect induced by the fiscal stimulus leads to an increase in interest rates by roughly 10 basis points. ${ }^{5}$

Figure 4: Impulse responses of the baseline specification. Notes: $90 \%$ confidence bands constructed by a wild bootstrap; quarterly frequency.
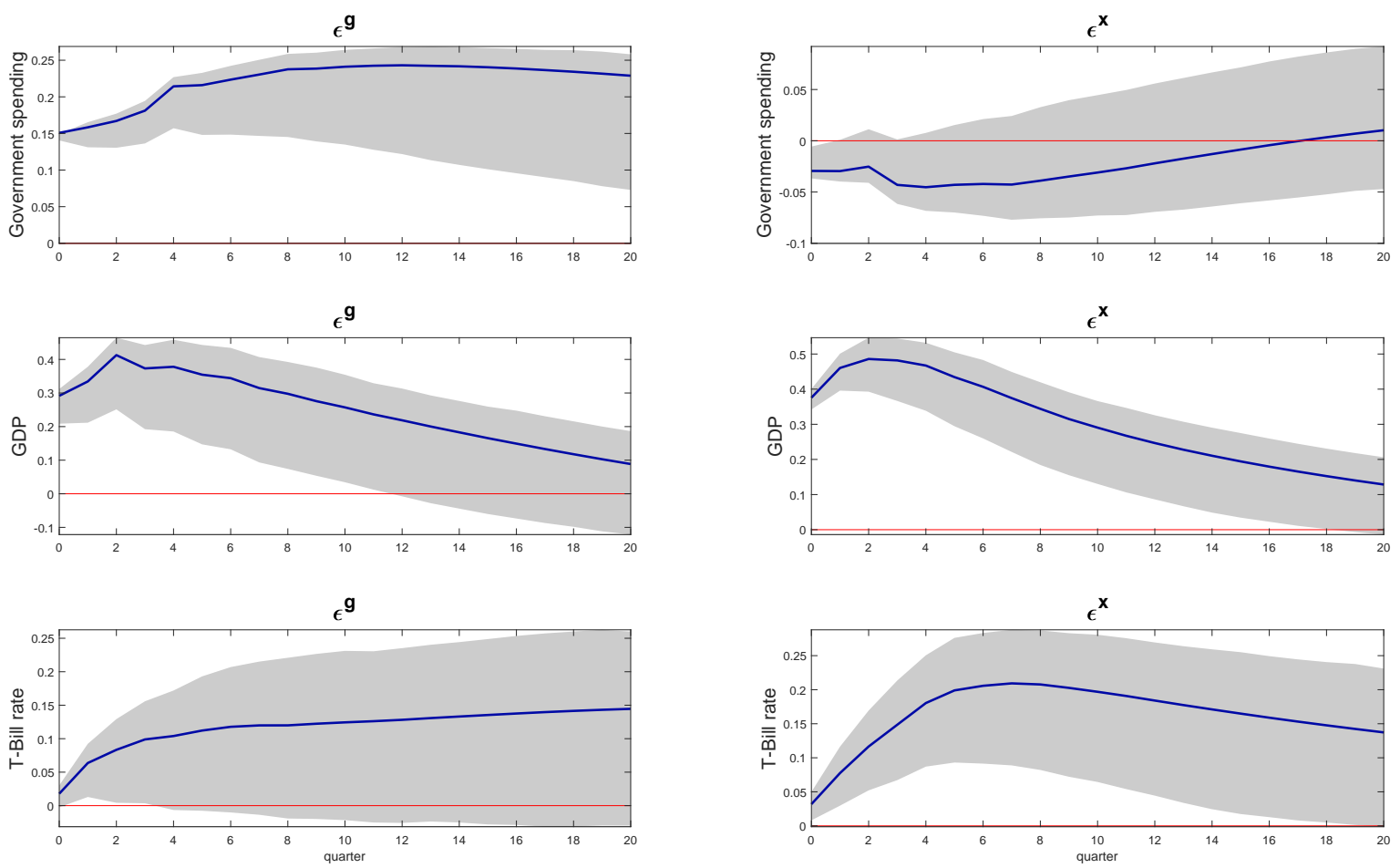

The second column summarizes the impact of the second shock, which is of interest because it shows the response of government spending to exogenous output variations. Output increases significantly by $0.4 \%$ in the same quarter the shock hits, and then in a hump-shaped manner. The peak response is at three quarters. Government spending falls upon impact. Although this effect is small and only borderline significant, the countercyclical behavior of government spending is of central importance for the size of the government spending multiplier (Caldara and Kamps, 2017). The government spending response is insignificant for the remaining horizon.

A key concept in the fiscal policy literature is the government spending multiplier. It is also of great importance for the policy debate because it gauges the effectiveness of surprise fiscal stimuli. It measures by how many dollars aggregate output increases when government spending increases exogenously by one dollar. A multiplier above one implies that an unexpected increase in government spending crowds-in private demand, whereas a multiplier below unity implies a crowding-out. We focus on the dynamics of the cumulative government spending multiplier, which measures the cumulative change

\footnotetext{
${ }^{5}$ As shown below, the government spending shock also leads to an increase in inflation, such that the interest rate response can be reconciled with a monetary authority following a standard Taylor-rule.
} 
in output relative to the cumulative change in government spending from the time of the government expenditure shock to a given period of the forecast horizon. We compute it as the ratio between the cumulative output and the cumulative government spending response as both variables are already normalized by potential output.

Figure 5: Baseline estimate of average government spending multiplier. Notes: $90 \%$ confidence bands; quarterly frequency.

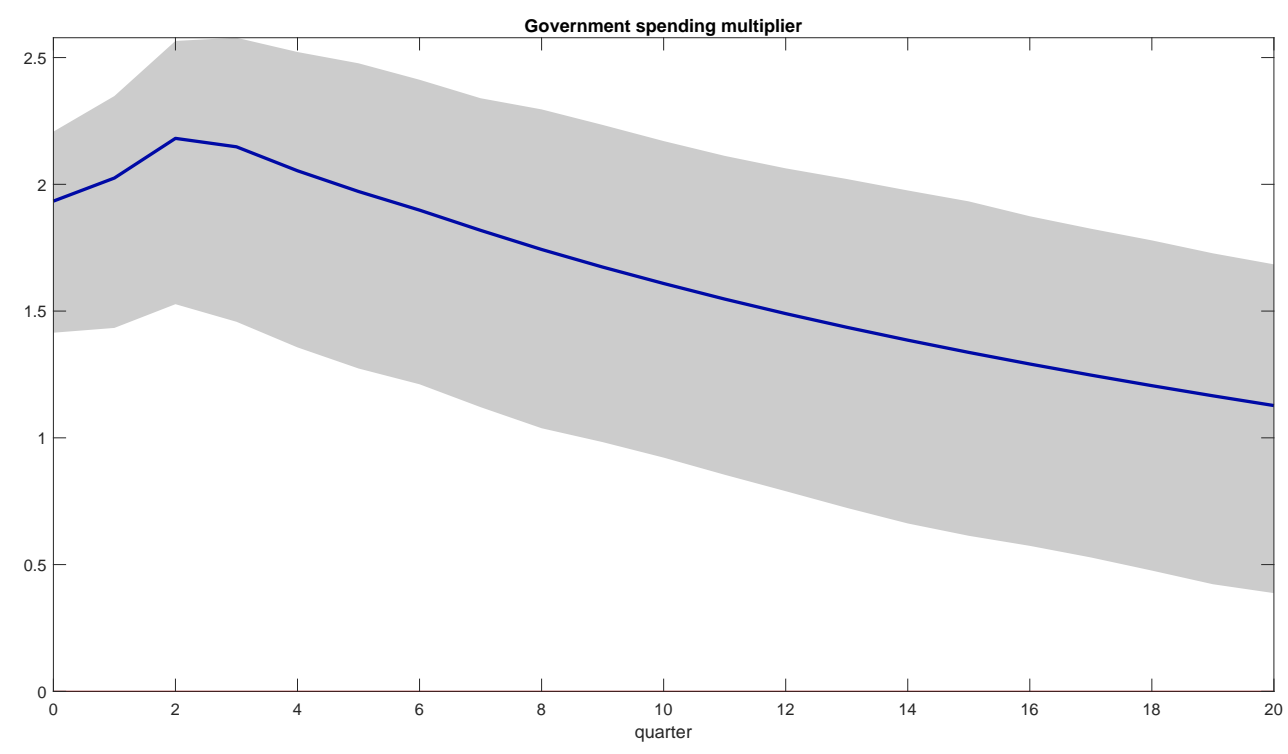

Figure 5 shows the estimated cumulative multiplier together with $90 \%$ confidence bands. The multiplier is larger than one over the whole forecast horizon, and statistically larger than unity for about ten quarters. It is 1.9 upon impact and it peaks two quarters after the shock. Subsequently, it decreases gradually and it is 1.1 after five years. Other studies find similar multiplier values (Ben Zeev and Pappa, 2017; Chodorow-Reich, 2019), but our estimate is larger than those typically found by applying timing-restrictions or using narrative accounts (Blanchard and Perotti, 2002; Ramey, 2011; Ramey and Zubairy, 2018). In the next section, we provide three empirical reasons for this difference.

One of the reasons is based on the insights of Caldara and Kamps (2017). The authors show that the size of the multiplier depends negatively on the contemporaneous elasticity of government spending to output. The intuition for this relation can be summarized as follows. There exists a positive comovement between government spending and output in the data, which any identification approach decomposes into a fraction explained by government spending shocks and a fraction explained by the remaining shocks of the SVAR. The timing assumption of Blanchard and Perotti (2002) implies that government spending does not contemporaneously respond to any other shock. Therefore, all the positive comovement in the data must be explained by the government spending shock. This leads to a spending multiplier of about one. If the systematic response of government spending increases, the remaining shocks explain a larger part of the positive comovement 
and the spending multiplier decreases. In contrast, if the systematic response decreases, that is, turns negative, the multiplier increases.

This is what we find. Our estimate suggests a significant contemporaneous response of government spending to output of -0.08 and, thereby, a relatively large multiplier. Caldara and Kamps (2017) estimate an impact reaction of spending to output of -0.13 and obtain spending multipliers larger than one, as well. ${ }^{6}$ They explain the negative reaction by nominal government spending being not fully indexed to inflation, implying that real government spending falls in response to an increase in inflation induced by the surprised output expansion. Thus, the negative elasticity should not be interpreted as an undertaken policy action but rather as a mechanical adjustment implied by price changes.

While Caldara and Kamps (2017) rely on external instruments to estimate the government spending to output elasticity and the corresponding multiplier, we use the heteroskedasticity in the data for estimating these relationships. We see our approach as complementing theirs. At the same time, ours gives full voice to the data, as it does not have to assume instrument exogeneity. Furthermore, it is not plagued by weak instruments problem for post-WWII data, it does not require the time-consuming construction of narrative instruments, and it can be readily applied to other countries.

\subsection{Economy-wide effects}

In this subsection, we analyze how government spending shocks affect consumption and investment to understand which components of private demand drive our multiplier estimates. Moreover, we discuss the effects on hours worked, employment, inflation, and government deficit. ${ }^{7}$ For this, we augment our baseline model by one of the additional variables at a time and summarize their impulse responses in Figure 6.

Private consumption expenditures increase significantly. The maximum response is reached two quarters after the shock occurred. This increase in consumption is driven by a significant and quantitatively similar rise in both of its components. Households purchase more non-durable and durable goods. The increase in private consumption following an exogenous increase in public consumption is difficult to rationalize using standard text-

\footnotetext{
${ }^{6}$ Caldara and Kamps (2017) estimate an impact multiplier between 0.9 and 1.2 depending on the specific form of the underlying fiscal rule. Similar to our estimates, they find that the spending multiplier peaks at values between 1.3 and 1.7 three-quarters after the shock.

${ }^{7}$ We use the Ramey and Zubairy (2018) dataset for the government deficit and the GDP deflator. Inflation is calculated as the quarterly percentage change of the GDP-Deflator. Total consumption expenditures are calculated as the sum of the FRED-codes PCND, PCESV, PCDG, where, again, the first two are used to calculate the non-durable consumption expenditures and the last one, PCDG, is our measure of durable consumption expenditures. For investment we use the codes FPI and PNFI, PRFI for (non-)residential investment, respectively. Data on total hours worked and employment in the nonfarm business sector are taken from Valerie Rameys' homepage. We normalize private consumption and investment expenditures by potential output. Hours worked and employment are normalized by total population and the government deficit is expressed relative to nominal GDP.
} 
Figure 6: Impulse responses of other variables of interest to a government spending shock. Notes: $90 \%$ confidence bands constructed by a wild bootstrap.
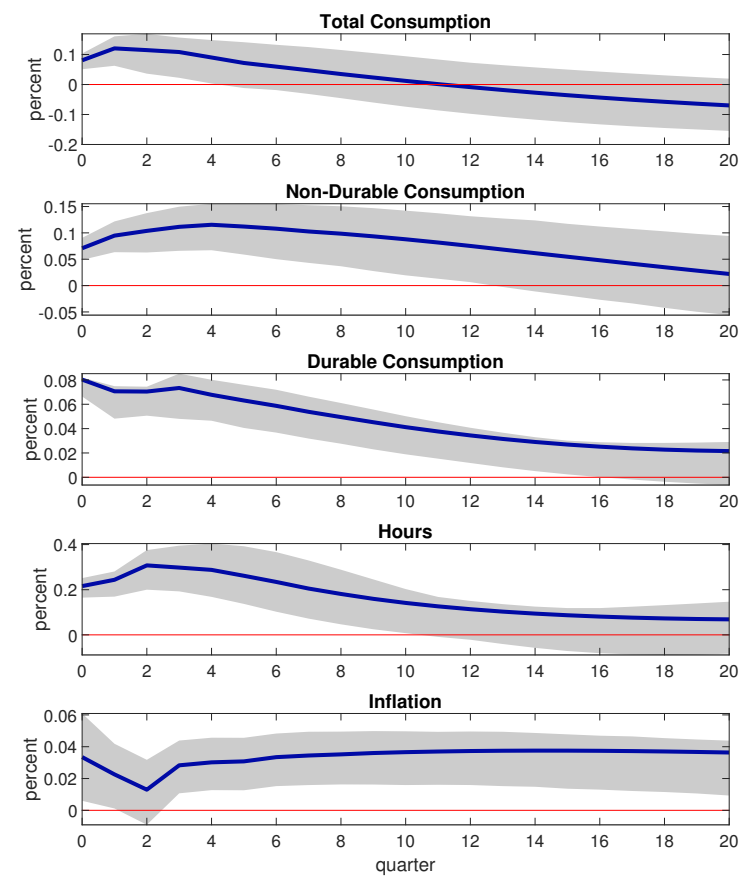
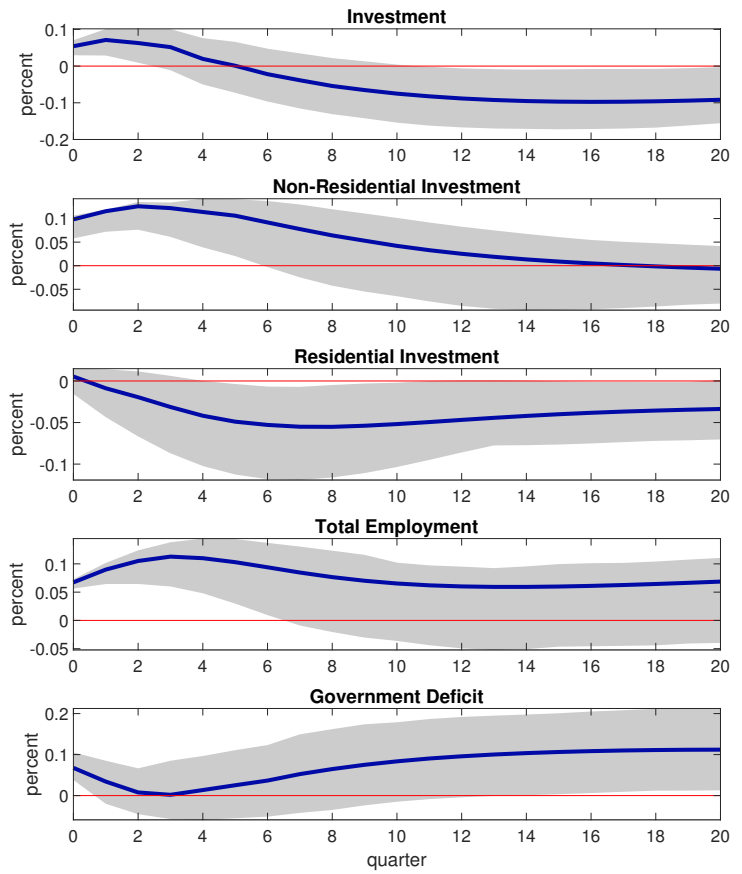

book models of the real business cycle or the New Keynesian paradigm. In these models, a government spending increase that is financed through higher lump-sum taxes in the future induces a negative wealth effect such that households increase savings and reduce consumption expenditures. However, extensions of the baseline model, such as limited asset market participation, countercyclical markups, consumption-leisure complementarity or different monetary-fiscal policy interactions might overturn these effects such that households consume more in response to a fiscal stimulus (Forni et al., 2009; Gali et al., 2007; Leeper et al., 2017). Our empirical evidence supports these theoretical modifications of the textbook model that limit the wealth effect due to an increase in government spending. ${ }^{8}$

Private Investment rises significantly only in the first couple of quarters. After about one year, the response is insignificant and turns significantly negative - although only borderline - after about three years. The negative investment response at longer horizons is mainly due to a significant fall in residential investment, whereas non-residential investment is above trend for about three years and significantly so for six quarters. Although hard to reconcile with theory, the (short-lived) positive investment response is in line with the empirical evidence presented by Ben Zeev and Pappa (2017). Taken together, the large multiplier in the first year of the surprise fiscal expansion seems to be driven by a crowding-in of household consumption and firm non-residential investment.

\footnotetext{
8 In general, the response of consumption to government spending shocks is the subject of a considerable debate with different results emerging from different identification schemes based on short-run restrictions and narrative identification schemes (Gali et al., 2007; Ramey, 2011).
} 
Furthermore, the government spending shock leads to a significant increase in hours worked, which reaches a maximum after two quarters. Besides its effect on the intensive margin, the spending shock also affects the extensive labor margin. Total employment increases significantly and the response shows a similar pattern as the one of hours worked. These responses are perfectly in line with the predictions of textbook models in which households supply more labor to compensate for future tax increases due to the fiscal expansion. The spending shock also has a positive impact on inflation, which increases significantly and persistently. The inflationary effect rationalizes the persistent increase in the T-Bill rate in response to a government spending shock documented in Figure 4 as the endogenous response of monetary policy. Finally, the public deficit significantly increases, suggesting that the identified fiscal surprise expansions are mainly deficit-financed.

\subsection{Robustness}

We now show that our results are robust to various alterations of the model and the data.

Augmented models. Figure 7 contains the multiplier corresponding to each of the ten models underlying Figure 6. It shows that adding other variables to the model leaves the multiplier largely within the $90 \%$ confidence bands of the baseline estimate. Moreover, all multipliers are larger than one, suggesting a crowding-in of private demand for at least 12 quarters.

Figure 7: Multipliers of augmented models. Notes: The figure shows the point estimates for the dynamic government spending multiplier of the augmented models (thin solid lines) and of the baseline model (thick line) and the $90 \%$ confidence bands for the baseline estimate.

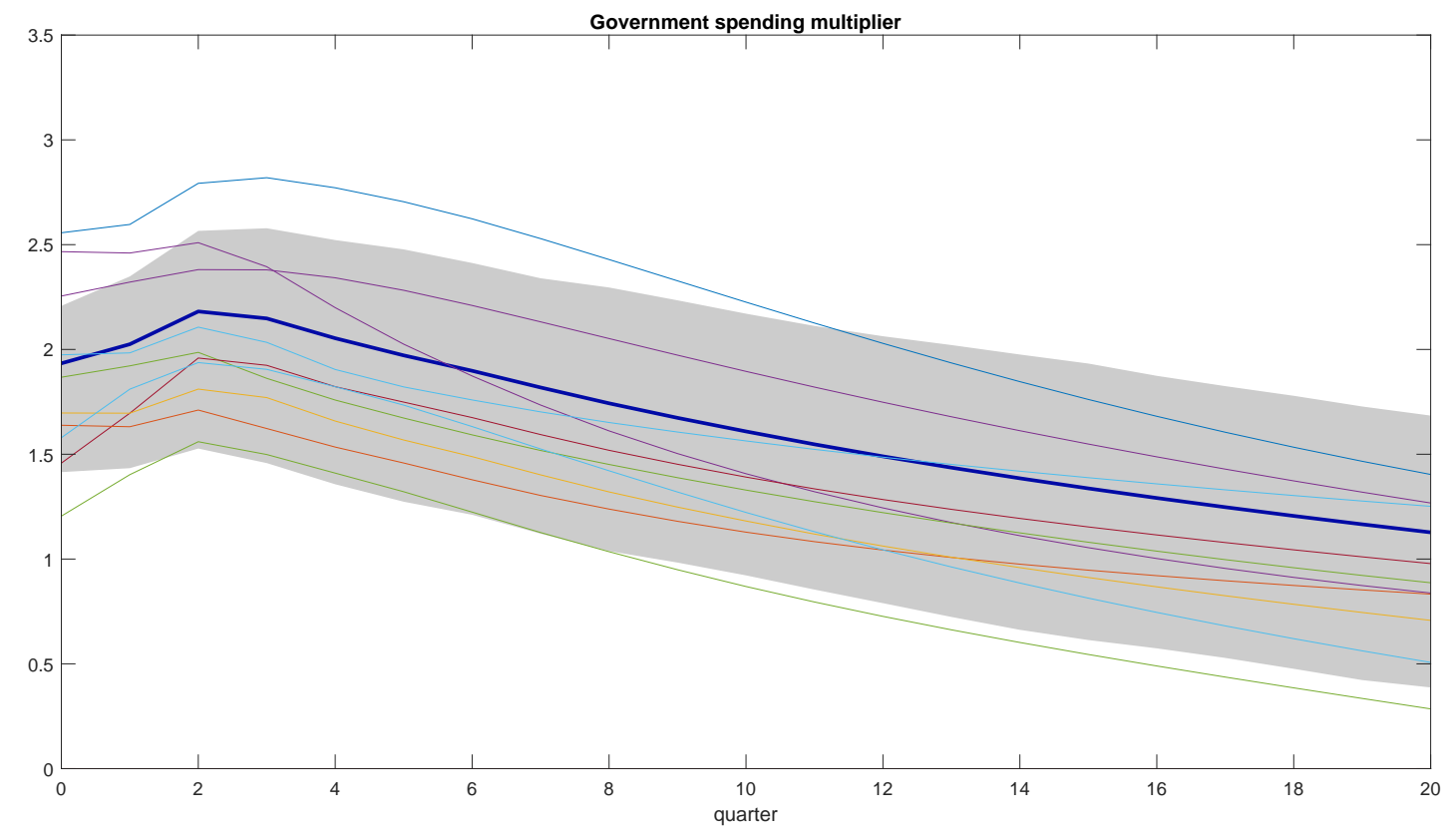


Tax policy. As the financing side of the fiscal stimulus might affect the size of the government spending multiplier, we control for tax policy in the estimation. In particular, the vector of observables now additionally includes real net tax revenues. The asterisked line in Figure 8 presents the corresponding estimate and compares it to the baseline multiplier point estimate (solid line) and confidence bands (shaded area). It shows that the main finding is not affected when controlling for tax policy, although the multiplier is slightly smaller compared to the baseline estimate. The cumulative one-year multiplier is around 1.7, similar to the value found by Caldara and Kamps (2017) who also include tax revenues as control variable. The fact that the multiplier is larger when controlling for monetary policy indicates that a model that does not account for confounding monetary policy interventions does not fully disentangle government spending from monetary shocks, which lowers the estimated impact of the fiscal stimulus. As Figure 4 shows, the interest rate indeed increases significantly in response to our identified government spending shock, suggesting that not accounting for this contractionary impetus lowers estimated government spending multipliers.

As an additional robustness test, we re-estimate the augmented four-variable models underlying Figure 6, but with taxes replacing the T-Bill rate in the set of the three baseline variables that are kept constant across models. For each modified extended model, we compute the government spending multiplier and compare it to the one of the threevariable model including taxes instead of the T-Bill rate. Figure 13 in the Appendix shows that the multipliers are greater than one. They tend to be smaller than the ones in the specifications with the T-Bill rate. Taken together, we conclude from these two sensitivity tests, that the implicit assumption in our baseline model, which excludes taxes, that government spending is largely orthogonal to tax policy at the quarterly frequency seems to be a reasonable approximation.

Fiscal foresight. As alternative sensitivity test, we account for fiscal foresight. This can arise when private agents do not just react to actual spending increases, but also to news about impending future spending plans. Then, the econometrician might not be able to recover the true unexpected spending shock because the information sets of agents and the econometrician are misaligned (Leeper et al., 2013). We address this issue by including a variable into the baseline SVAR that captures expectations about future policy actions. Specifically, we use real-time professional forecasts for government spending, which is a spliced series of government spending forecasts provided by the Greenbook (1966-2004) and the Survey of Professional Forecasters (1982-2016). We extend the series provided by Auerbach and Gorodnichenko (2012), which covers 1966 to 2008, to include the Great Recession and the following years. Figure 8 shows that the results (dashed line) are similar to the baseline estimates of the dynamic spending multiplier. In particular, the multiplier is larger than one. This analysis suggests that our baseline findings are quantitatively not strongly affected by fiscal foresight. 
Zero lower bound. The baseline sample includes the Great Recession and the subsequent zero lower bound period. To investigate whether the results are robust to excluding these years, we estimate the baseline model ending the sample in 2007Q4. As the dotted line shows, the results are hardly affected when excluding the crisis and zero lower bound period. The estimated multiplier is within the confidence interval of the baseline estimate.

Figure 8: Robustness of the estimated government spending multiplier. Notes: The figure shows the cumulative spending multipliers of the baseline model (thick line) together with its $90 \%$ confidence bands and of a model that controls for fiscal foresight using forecast errors (thin dashed line), for the zero lower bound excluding the data after 2007 (thin dotted line) and for taxes (asterisked line).

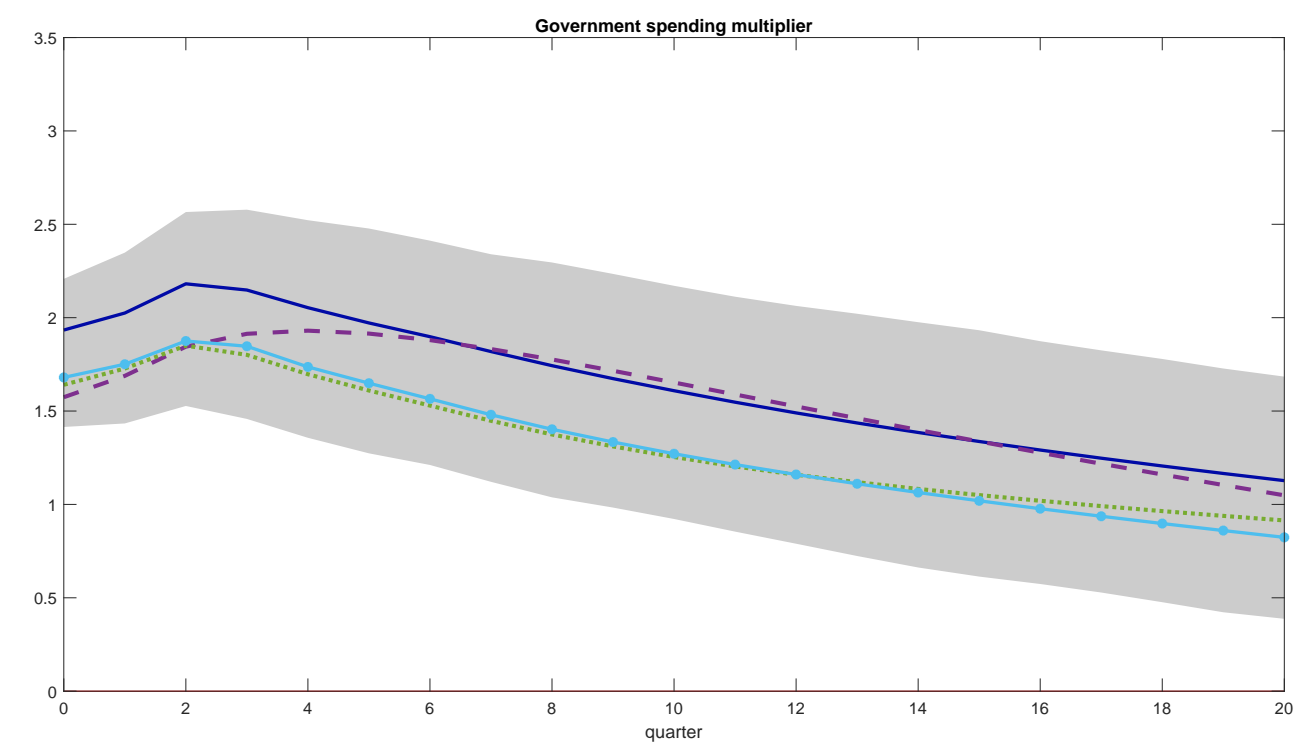

Omitted variables. A more general concern with the relatively small model is that it omits relevant variables and is potentially noninvertible (Stock and Watson, 2018). The limitation to smaller models is a well-known drawback of MS models, which are computationally intensive given their strong nonlinearity and treatment of the transition variable as latent. At the same time, this agnostic modeling of heteroskedasticity gives full voice to the data as it is not based on a priori definitions of transition variables, points or functions. Moreover, the sensitivity analysis in this subsection, which adds many control variables to the baseline model and shows that the main results are unchanged, suggests that our estimates do not suffer from omitted variable bias.

\section{Results in perspective}

In this section, we compare our results to the literature and analyze the implications of our modeling choices for the size of the estimated multiplier. Our framework differs from Blanchard and Perotti (2002) and Ramey (2011) along two important dimensions. First, 
we use a different identification scheme, which is based on heteroskedasticity, whereas they use either a timing assumption or news on military spending as instrument. Second, our identification strategy implies that we estimate a nonlinear model that takes into account changes in the variances of the error terms, while they use linear models.

To quantify the importance of each dimension for explaining our results, we concentrate on the timing assumption first. It is usually justified by the fact that policy makers need time to decide on, approve, and implement changes in fiscal policy. To assess whether it is supported by the data, we set the contemporaneous response of government spending to exogenous output increases to zero, that is, we set $b_{12}=0$ in restriction $R 1$, and estimate this model against one with unrestricted impact matrix $B$. Table 5 displays the $p$-value of the corresponding likelihood-ratio (LR) test. The data do not reject $R 1$. However, the test result needs to be treated with caution as the power of the test is unclear in our sample. Moreover, the evidence in Table 5 conflicts with Figure 4, which shows a borderline significant negative response of government spending to output shocks. Taken together, we thus conclude that the data do not speak clearly in favor or against the timing assumption, in line with the evidence in Bouakez et al. (2014) and Lewis (2019).

Table 5: LR tests. Note: The table shows the null and alternative hypothesis for tests of $R 1$ and $R 2$ on the $B$-matrix and the associated degrees of freedom (df) and $p$-values.

\begin{tabular}{llcc}
\hline Null hypothesis & Alternative hypothesis & df & $p$-value \\
\hline$R 1: b_{12}=0$ & $B$ unrestricted & 1 & 0.382 \\
$R 2: b_{12}=b_{13}=b_{23}=0$ & $B$ unrestricted & 3 & 0.573 \\
$R 2: b_{12}=b_{13}=b_{23}=0$ & $R 1: b_{12}=0$ & 2 & 0.539 \\
\hline
\end{tabular}

In the next step, we impose two more restrictions that help us approaching a justidentified model in a linear setting; that is, without heteroskedasticity, against which we can compare the effect of modeling changes in volatility explicitly. In $R 2$, we impose additional zeros on the impact reaction of government spending and output to identify a monetary policy shock, that is, we set $b_{12}=b_{13}=b_{23}=0$. This implies a Cholesky decomposition. The additional restrictions are motivated by a literature on the identification of monetary policy shocks (Christiano et al., 1999), which assumes that prices are rigid and that the real economy is affected by such shocks with a time lag. The data do not reject $R 2$, neither against the alternative of unrestricted $B$, nor against $R 1$ (see Table $5)$.

Table 6 shows the estimated cumulative output multiplier corresponding to the baseline model with unrestricted $B$ and to the model under $R 1$ and $R 2$, respectively, for selected years of the response horizon. In line with the argument of Caldara and Kamps (2017), the estimated multiplier decreases for all years under $R 1$. The decline is substantial. The estimate for the first year drops from 2.15 to 1.43. For year 5, the unrestricted model suggests a crowding-in, while MS-R1 implies a crowding-out of private demand with 
a multiplier below unity. In contrast, the two additional exclusion restrictions in MS-R2 have essentially no extra effect on the dynamic multiplier. Thus, together with the evidence from the LR-tests, we maintain $R 2$ and estimate a just-identified linear model. The estimates for the dynamic multiplier shown in the next row drop further when neglecting the heteroskedasticity. It declines to one in the first year and falls below unity for the remaining years. Summing up, the baseline unrestricted MS model yields a multiplier that is roughly twice as large as the one implied by a linear-recursive model. About twothirds of that difference can be explained by differences in the identification scheme and the remaining fraction by alternative ways of dealing with changes in volatility.

Table 6: Comparison of total government spending multipliers. Note: The table shows the cumulative total government spending multiplier for Markov switching (MS) and linear models for different model specifications and identification schemes. In the MS baseline model, the impact matrix $B$ is unrestricted. For $R 1: b_{12}=0$ and for $R 2: b_{12}=b_{13}=b_{23}=0$.

\begin{tabular}{lccccc}
\hline \multicolumn{6}{c}{ Response horizon in years } \\
Model & 1 & 2 & 3 & 4 & 5 \\
\hline Government spending shock & & & \\
MS unrestricted & 2.15 & 1.82 & 1.55 & 1.34 & 1.17 \\
MS-R1 & 1.43 & 1.22 & 1.06 & 0.92 & 0.81 \\
MS-R2 & 1.40 & 1.21 & 1.06 & 0.93 & 0.82 \\
Linear-R2 & 1.01 & 0.91 & 0.83 & 0.76 & 0.69 \\
Military spending shock & & & & \\
MS-R2 & 0.92 & 0.91 & 0.85 & 0.79 & 0.73 \\
Linear-R2 & 0.78 & 0.63 & 0.56 & 0.53 & 0.50 \\
\hline
\end{tabular}

Next, we compare the baseline estimate for the government spending multiplier to the output effects of military spending shocks, both in a heteroskedastic and in a linear model, to understand how the size of the multiplier depends on the public spending component considered and whether the finding of a larger multiplier in a time-varying volatility model generalizes to this type of shocks. A number of studies use a narrative approach (Ramey, 2011, Barro and Redlick, 2011 and Ramey and Zubairy, 2018). In this literature, wars and the associated expenses are assumed to be exogenous to current economic conditions. We follow this idea in our framework and augment the three-variable model with military spending, which we order first. In other words, we assume that military spending is contemporaneously exogenous with respect to the three baseline variables, for which we maintain the recursive identification. This assumption is also applied by, among others, Barro and Redlick (2011) and Hall (2009).

The bottom two rows of Table 6 show that the total government spending multiplier induced by military spending shocks is smaller than the total government spending multiplier generated by total government spending shocks, and below one throughout the full response horizon. As discussed in the literature, this might be due to the different nature of these shocks, which are typically not tailor-made to stimulate the economy, to the 
observation that large increases in military spending are often accompanied with other macroeconomic policies, like price controls, or to other confounding developments such as rising patriotism. Moreover, the comparison between both models for military spending shocks shows that the MS model implies a larger multiplier throughout the five years.

The second finding - together with the same observation for the multiplier produced by total government spending shocks - deserves further attention. It suggests that the estimated multiplier does not only depend on the identification scheme but also on the way the model deals with heteroskedasticity. Specifically, it seems that the generalized models, which account for time-varying volatility, imply larger estimates than the linear models, which ignore heteroskedasticity. In analogy to standard regression analysis, this outcome is intuitive as generalized models weigh observations differently than homoskedastic models. While the former give more weight, or likelihood (see Eq. 4), to observations with low error variance than to observations with high error variance, the latter treat them equally. This difference does not just affect inference but also point estimates.

The reasoning opens the door for two possible explanations for the larger multipliers implied by the heteroskedastic models. First, it could be that the multiplier is the same in both volatility regimes and that the larger estimates for the MS models are only due to sampling error in the high volatility regime, which erroneously implies a lower multiplier for these observations but, luckily, the estimate is down-weighted because of the associated higher uncertainty. If this is the case, it seems reasonable to use the estimates from the more efficient MS model. Lütkepohl and Schlaak (2018) show that heteroskedastic VAR models typically outperform linear models in terms of estimation precision of the structural parameters when the data feature changes in volatility.

Second, it may be that the multiplier is state-dependent. In particular, if the multiplier is larger in the low than in the high volatility regime, a Markov switching in heteroskedasticity model with state-independent impact matrix would yield a larger average multiplier than a linear model. It would give more weight to the larger multiplier in the low volatility state as this estimate is associated with lower sampling uncertainty. We investigate this possibility next.

\section{The state-dependent effects of government spending shocks}

In this section, we relax the assumption of constant impact effects across volatility regimes. We allow for state-dependent effects to analyze whether the dynamic impact of government spending shocks depends on the level of volatility of an economy. This is a central implication of seminal theoretical work, which shows that demand policy is less effective when structural shock variances increase. In a situation of higher volatility, firms might postpone hiring and investment decisions Bloom, 2009. Bloom et al. (2018) "[...] highlight how uncertainty shocks lead to time-varying policy effectiveness. At the instant an 
uncertainty shock hits, policy is not as effective relative to normal times (p. 1061)." The article models uncertainty through a Markov processes for the structural shock variances. Similarly, Bernanke (1983) and McDonald and Siegel (1986) show that higher uncertainty raises the real option value of waiting before making investment decisions. Moreover Additionally, Basu and Bundick (2017) and Fernandez-Villaverde et al. (2011) point out that when the time-varying second moment of structural shocks increases, there is a stronger precautionary savings motive by consumers. These theoretical models typically interpret such an increase in shock variances as an increase in uncertainty.

The Markov switching in heteroskedasticity model provides a natural way to test these prediction as it allows for time-varying shock variances. Moreover, the framework provides advantages over models with exogenously determined regimes, such as threshold or smooth transition models, as it treats the potential transition variable(s) as latent. It is more agnostic about the state determination and reduces the risk of misspecification of the transition variable, function, or points. Relative to threshold models it is more flexible as it allows for mixtures of states. ${ }^{9}$

\subsection{Identification and volatility regimes of state-dependent model}

To implement the dependency of the multiplier on the volatility regime, we generalize the decomposition in (3) as in Bacchiocchi and Fanelli (2015) to

$$
\Sigma_{u}(1)=B B^{\prime} \quad \text { and } \quad \Sigma_{u}(2)=(B+Q) \Lambda_{2}(B+Q)^{\prime}
$$

where $Q$ is a $n \times n$ coefficient matrix that is added to the impact matrix $B$. Now, the observable changes in the reduced form covariance matrix between regimes can be explained by changes in the impact effects, by changes in volatility of the structural shocks (as before), or by a combination of both. The decomposition in (3) is a special case of (5) with the restrictions $Q=0_{n \times n}$. As this special case was just-identifying $B$, it follows that the decomposition (5) is not (locally) unique and we need to place some restrictions on the elements of $B, Q$ and $\Lambda_{2}$. Specifically, the decomposition contains $n(n+1)$ symmetry restrictions but $2 n^{2}+n$ elements, such that we need $n^{2}$ further restrictions.

These are driven by our research question. As we are particularly interested in the state-dependent effects of government spending shocks, we let their impact effects change across regimes and assume others to be state-invariant. In detail, we estimate $q_{21}$, which is the main parameter of interest. Under the assumption that the first shock is the spending shock, this coefficient measures the state-dependent impact of exogenous increases in government spending on output. Moreover, we allow the impact of $\epsilon_{t}^{g}$ on government

\footnotetext{
${ }^{9}$ A related literature uses threshold or smooth transition models to analyze whether the impact of fiscal policy depends on the slack in the economy or on the level of the monetary policy rate (Auerbach and Gorodnichenko, 2012; Ramey and Zubairy, 2018).
} 
spending to change by $q_{11}$ when switching to state 2 . These two formulations imply that the size of both the impact of government spending shocks on government spending and on output and the relative impacts can (but does not need to) differ across regimes. In other words, they allow for a change in the shock size across regimes that leaves the ratio of the output to the spending impact response constant, for a change in the relative impact effects (in either direction) with constant shock size, or a combination of changes in shock size and relative impact effects. Regarding the other two shocks, we estimate $\lambda_{22}$ and $\lambda_{23}$, implying that these structural variances may change across regimes.

Finally, we set $b_{13}=b_{23}=0$, based on the LR-tests in Table 5. In contrast, we leave $b_{12}$ unconstrained. Although the LR-test does not reject the zero assumption for this parameter, the confidence bands of the impulse response of government spending do (see Figure 4). Moreover, Table 6 and Caldara and Kamps (2017) show that small differences in this parameter can have large effects on the size of the multiplier. To summarize, we impose the following restrictions:

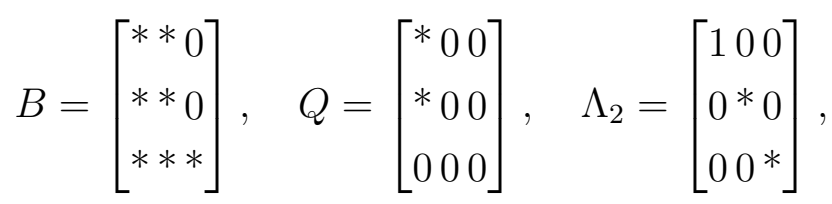

where asterisks denote unrestricted elements. These restrictions assure that the conditions for local identification are satisfied.

To see whether these restrictions locally identify the structural model, we follow Bacchiocchi and Fanelli (2015) and check whether the matrix ${ }^{10}$

$$
\left(I_{2} \otimes D_{K}^{*}\right)\left(\begin{array}{ccc}
\left(B \otimes I_{K}\right) & 0_{K^{2} \times K^{2}} & 0_{K^{2} \times K} \\
2(B+Q) \Lambda \otimes I_{K} & 2(B+Q) \Lambda \otimes I_{K} & ((B+Q) \otimes(B+Q)) U_{K}^{\prime}
\end{array}\right)\left(\begin{array}{ccc}
S_{B} & 0_{K^{2} \times a_{Q}} 0_{K^{2} \times a_{\Lambda}} \\
0_{K^{2} \times a_{B}} & S_{Q} & 0_{K^{2} \times a_{\Lambda}} \\
0_{K^{2} \times a_{B}} & 0_{K^{2} \times a_{Q}} & S_{\Lambda}
\end{array}\right)
$$

has full rank using 100,000 matrices drawn from the uniform distribution on the interval between -10 and 10 . We find that the rank condition is satisfied for all draws.

\subsection{Results of state-dependent model}

While a priori we again do not know the ordering of the shocks, we can determine them after estimation based on the decomposition of the forecast error variances. Table 7 shows that the ordering of the shocks is the same as before. The government spending shock is ordered first, explaining on average $97 \%$ of the variability of government spending across both states (using the smoothed state probabilities as weights) upon impact. The other

\footnotetext{
${ }^{10} D_{K}^{*}$ denotes the is the Moore-Penrose inverse of the duplication matrix, $S_{B}, S_{Q}, S_{\Lambda}$ denote selection matrices on the parameters $B, Q$ and $\Lambda$, respectively, $U_{K}$ denotes a $K \times K^{2}$ full row rank matrix with the property that $U_{K}^{\prime} \operatorname{diag}(M)=\operatorname{vec}(M)$ for a diagonal matrix $M$ and $a_{B}, a_{Q}, a_{\Lambda}$ denote the free parameters in $S_{B}, S_{Q}, S_{\Lambda}$, respectively
} 
two structural shocks follow with variance contributions to GDP and the T-Bill rate of $70 \%$ and $93 \%$, respectively, on average across states.

Table 7: Weighted impact forecast error variance decomposition.

\begin{tabular}{lccc}
\hline & \multicolumn{3}{c}{ Shock } \\
Variable & $\epsilon_{t}^{g}$ & $\epsilon_{t}^{x}$ & $\epsilon_{t}^{r}$ \\
\hline Gov. spending & 0.97 & 0.03 & 0.00 \\
GDP & 0.30 & 0.70 & 0.00 \\
T-Bill rate & 0.00 & 0.07 & 0.93 \\
\hline
\end{tabular}

Figure 9 shows the smoothed state probabilities of the state-dependent model for the low and high volatility state in the upper and lower panel, respectively. The state probabilities are relatively similar to those of the baseline model (see Figure 2). The state-dependent model is more often in the high volatility state than the baseline model but the correlation between either of the smoothed probabilities between both models is 0.85. Again, the figure clarifies that the volatility states are not the same as recessions or the period of the zero lower bound on interest rates (although the partially overlap with these episodes). This is important to bear in mind when interpreting our estimated state-dependent effects of government spending shocks as both, recessions and the zero lower bound, are shown to increase the effectiveness of fiscal interventions (Auerbach and Gorodnichenko, 2012; Christiano et al., 2011), whereas higher uncertainty is hypothesized to lower it (Bloom et al., 2018). This overlap then also implies that our estimates are likely to provide a lower bound for the dependency of the efficacy of fiscal interventions on the level of volatility.

Figure 10 presents the state-dependent impulse responses to a government spending shock of one standard deviation in the low volatility regime (left column) and in the high volatility regime (right column). ${ }^{11}$ Qualitatively, the dynamics are similar in both states. Government spending gradually and persistently increases. GDP responds positively upon impact, peaks at three quarters, and slowly returns back to the level where it would have been without the shock. The output responses are significantly larger than zero for about two years. Similarly, the T-Bill rate increases significantly in both states. Quantitatively, however, there are substantial differences in both the absolute and relative responses of government spending and output between regimes. The increase in spending is about twice as large in the high volatility regime, consistent with the earlier evidence that government spending shocks are larger during these episodes. In contrast, the output response is only mildly larger in state two. Taken together, the point estimates suggests that the government spending multiplier is substantially lower in the high volatility regime.

\footnotetext{
${ }^{11}$ The model produces reasonable dynamics following the monetary policy shock, which are qualitatively similar to the responses to the third shock in the baseline model. Moreover, the output shock triggers a gradual increase in the T-Bill rate, whereas government spending declines. Moreover, an exogenous increase in the T-Bill rate leads to a persistent decline in output and government spending.
} 
Figure 9: Smoothed state probabilities of state-dependent model. Notes: The figure shows the smoothed state probabilities of the state-dependent model for the low and high volatility state in the upper and lower panel, respectively.
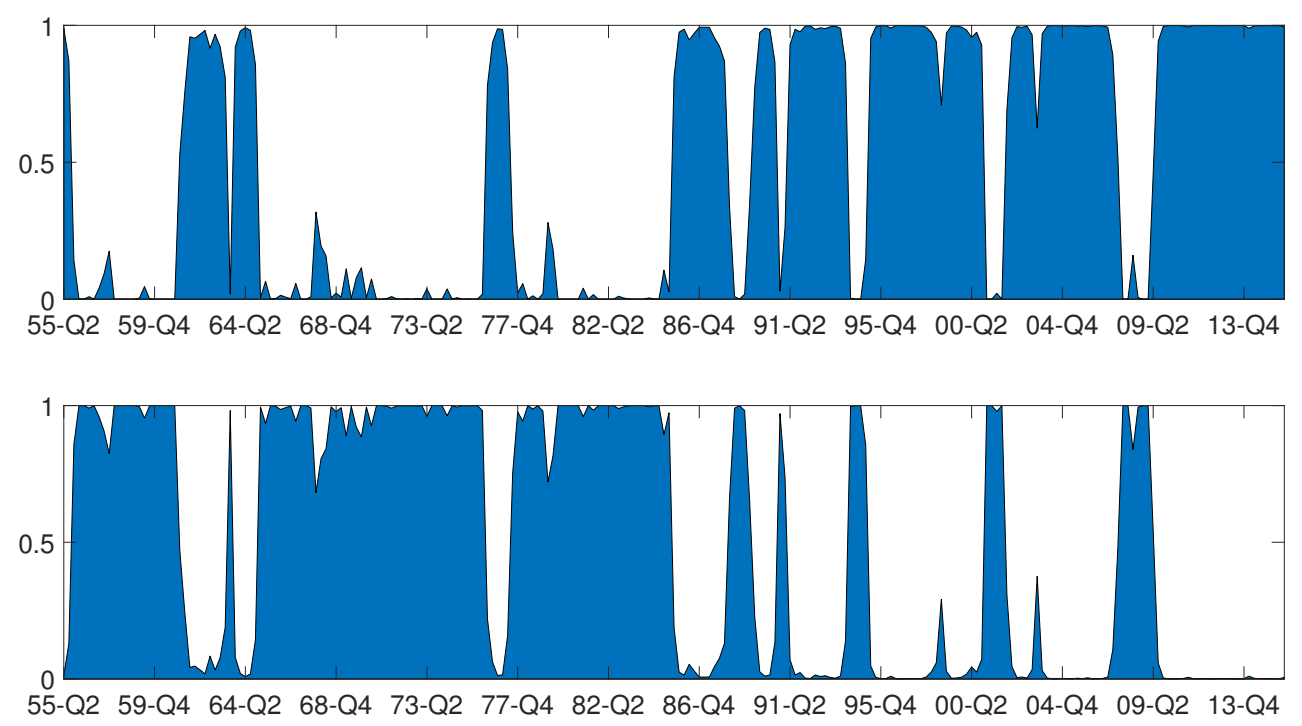

This is confirmed by Figure 11. The solid lines show the cumulative government spending multiplier in both regimes, together with $90 \%$ confidence bands. In the low volatility regime (left panel), the multiplier is two upon impact and increases slightly in the subsequent quarters. It reaches a maximum one year after the shock occurred. Then, it gradually declines but is still significantly larger than one after two years. At the end of the response horizon, it falls to one. The multiplier is substantially smaller in the high volatility regime. It is 1.5 on impact and the effect is only borderline significantly larger than one. After five years, the value is 0.5. The formal comparison between regimes in Figure 12 shows that the multiplier is statistically significantly larger in the low volatility regime for the full horizon.

To assess the sensitivity of the state-dependency to the identification scheme, the dashed lines in Figure 11 show regime-specific multipliers using a Cholesky decomposition in both states with government spending ordered first, followed by output and the T-Bill rate. Relative to the decomposition (5) with (6), this identification strategy implies that the change in variances is shifted entirely to $Q$, that the elasticity of government spending to output is zero in both regimes, and that the response of monetary policy is state-dependent. Again, the multiplier is larger in the high than in the low volatility regime and this difference is statistically significant (we omit the respective error bands for visibility). Moreover, in both states the point estimate is below the one implied by the generalized decomposition, in line with the argument that the timing assumption of Blanchard and Perotti (2002) produces lower multipliers. 
Figure 10: State-dependent responses to government spending shock. Notes: The figure shows the responses to a government spending shock of one standard deviation in the low volatility regime (left column) and in the high volatility regime (right column). 90\% confidence bands constructed by a wild bootstrap.
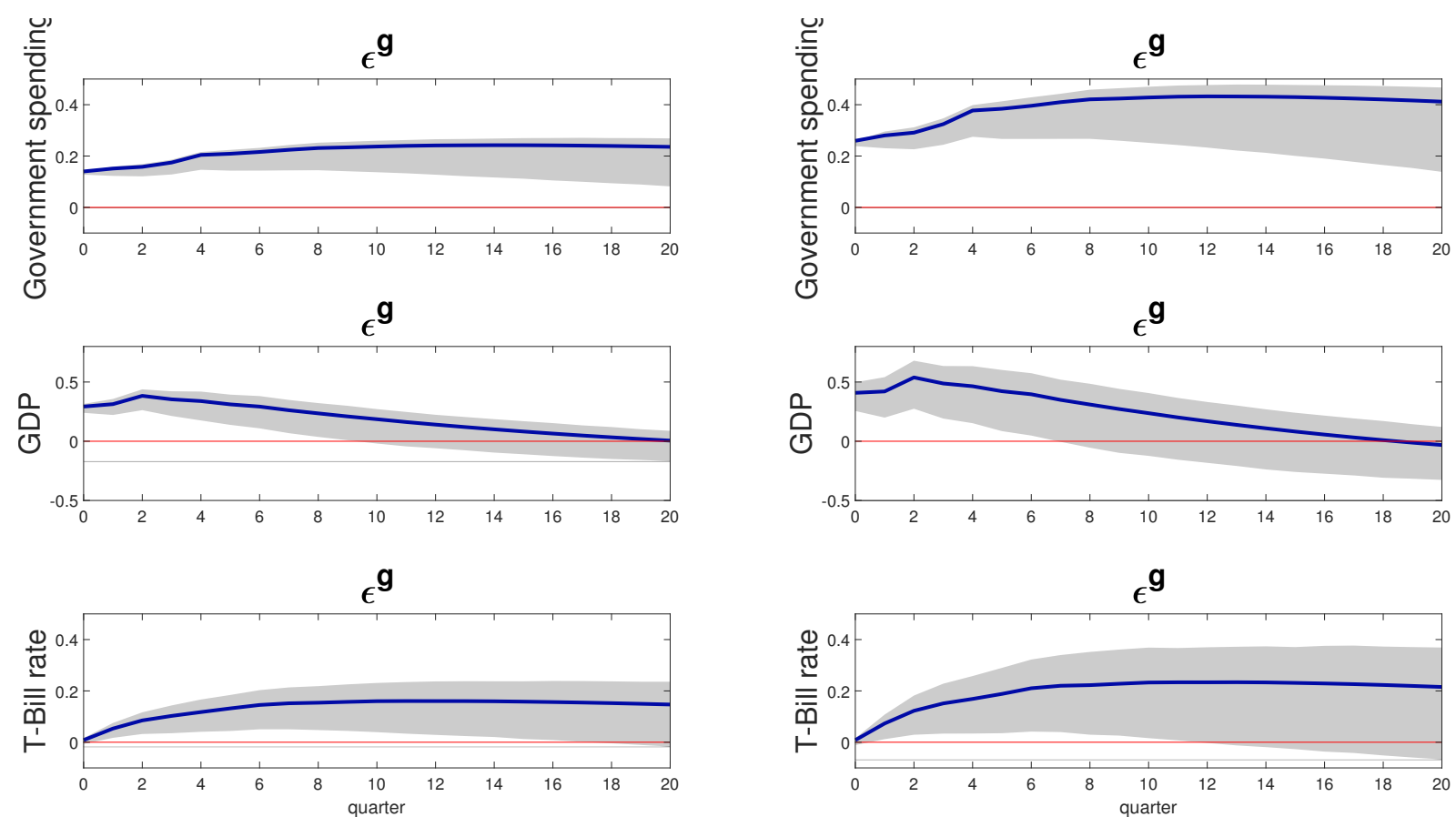

Figure 11: State-dependent government spending multipliers. Notes: The figure shows the government spending multiplier in the low volatility regime (left panel) and in the high volatility regime (right panel). The solid line and shaded area correspond to the point estimate and $90 \%$ confidence bands, respectively, for decomposition (5) and the dashed line refers to the point estimate implied by a Cholesky decomposition with ordering $y_{t}=\left[g_{t}, x_{t}, r_{t}\right]^{\prime}$.
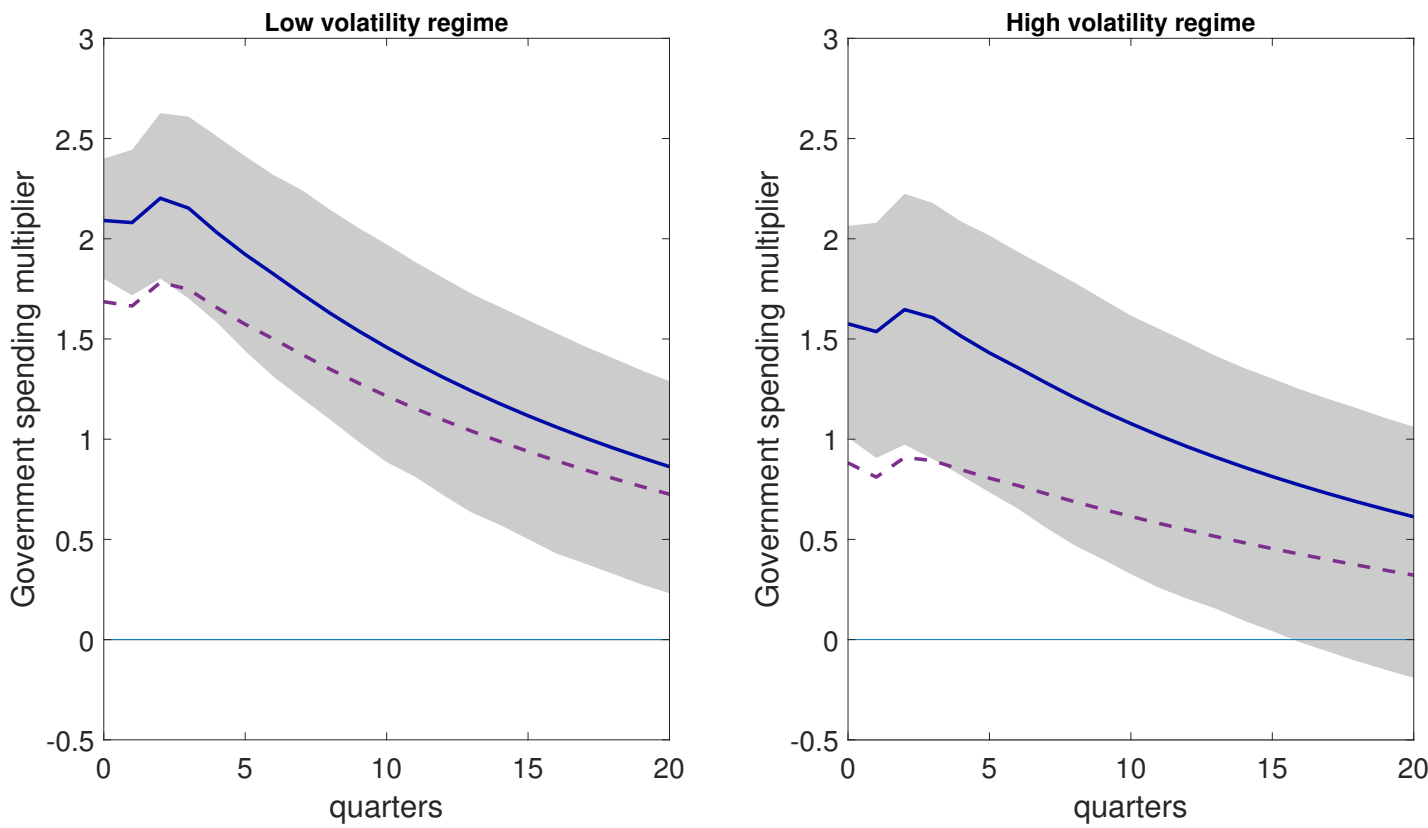
Figure 12: Difference between state-dependent government spending multipliers. Notes: The figure shows the difference between the government spending multiplier in the low volatility regime (left panel of Figure 11) and in the high volatility regime (right panel of Figure 11). The solid line and shaded area correspond to the point estimate and $90 \%$ confidence bands, respectively, for decomposition (5) and the dashed line refers to the difference between the statedependent point estimates implied by a Cholesky decomposition with ordering $y_{t}=\left[g_{t}, x_{t}, r_{t}\right]^{\prime}$ as displayed in Figure 11.

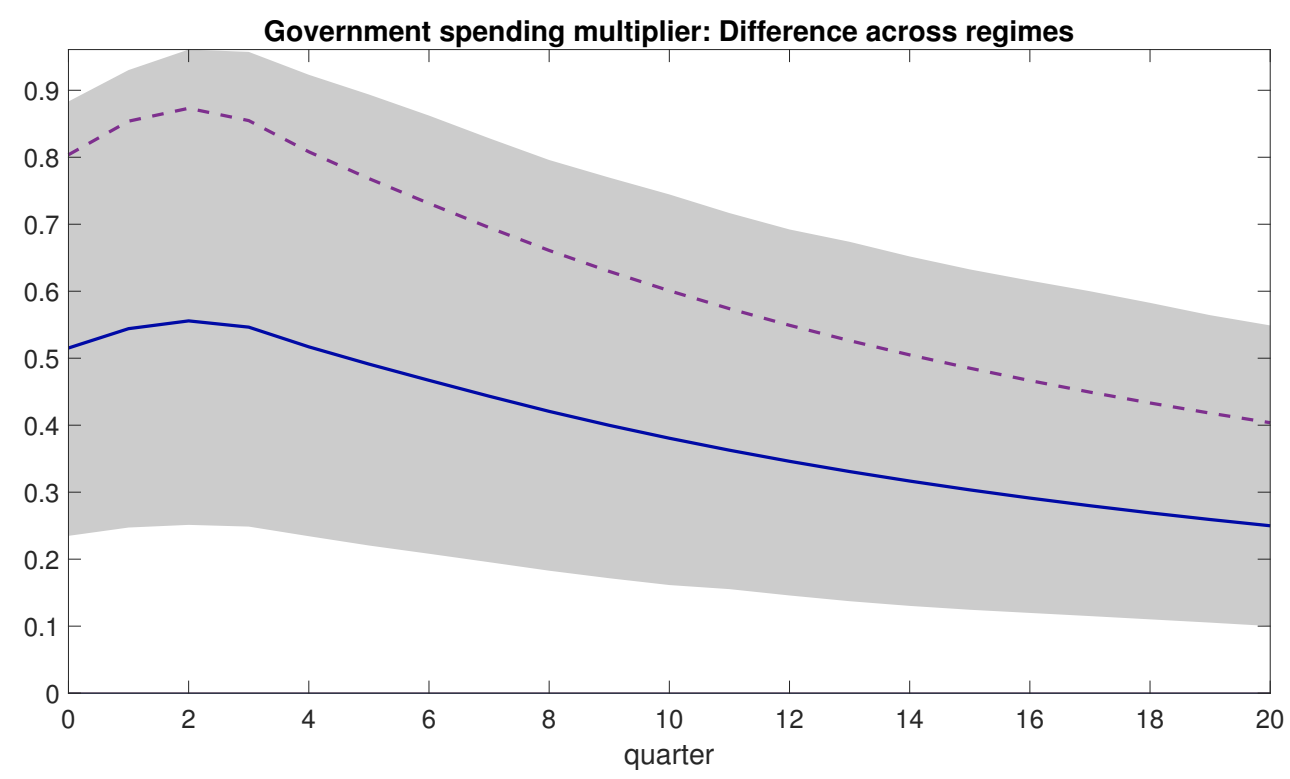

Summarizing, we find evidence for state-dependent effects of fiscal policy. The government spending multiplier is significantly larger when volatility is low, consistent with the theoretical predictions of Bloom et al. (2018). For the general decomposition, the statedependent multipliers span the average multiplier implied by the unrestricted MS model (see Table 6). On impact, for example, they are 2.1 and 1.6 in state 1 and 2, respectively, and 1.9 on average. For the recursive ordering, they are 1.7 and 0.9 on impact in state 1 and 2 , respectively, and 1.4 on average.

The findings also rationalize that we find larger average multipliers in the heteroskedastic than in the linear models. The average multipliers in the first year, for example, are 1.4 and 0.9 for the MS models, while they are 1.0 and 0.8 for the linear models. These differences reflect differences in the weighting of the state-dependent effects. The smaller multiplier estimates for the high uncertainty regime obtain less weight in the MS models than in the linear models, producing larger average estimates.

These findings contain important policy implications. Combined with the smoothed state probabilities (see Figure 9), they imply that fiscal policy tended to be less effective in the first part of the sample because there was a larger probability of being in the high volatility regime. In contrast, fiscal policy was more effective during the Great Moderation and the years that followed the Great Recession. This might be driven by the more stable policy environment in the second part of the sample. By following a well-defined and transparently communicated rule-based behavior, such a policy framework can reduce 
uncertainty and simplify expectation formation by private agents. When future policy interventions and output fluctuations are easier to predict, the precautionary savings motive of households is reduced and firms' region of inaction shrinks.

Moreover, because the low volatility regime also includes the period of constrained monetary policy at the end of the sample, our results support the view that fiscal policy is more effective when interest rates are at the zero lower bound, in line with recent empirical evidence by Miyamoto et al. (2018) and Ramey and Zubairy (2018). In contrast, as high volatility states partially coincide with NBER recessions, our findings suggest that fiscal policy may be less effective during periods of economic slack.

\section{Conclusion}

We estimate the macroeconomic effects of government spending shocks in the US. We identify the shocks through an agnostic identification scheme that exploits time-varying volatility in quarterly post-WWII data modeled through a Markov switching approach.

We find that the average output effects of exogenous spending increases are positive and that the multiplier is significantly and persistently above one. This is mostly due to a crowding-in of private consumption. The estimated average multiplier is larger than multipliers estimated based on timing-restrictions or exogenous increases in military spending. There are three main reasons that explain these differences. First, we find that government spending responds contemporaneously countercyclical to exogenous changes in output. As the size of the government spending multiplier is negatively affected by the size of this elasticity (Caldara and Kamps, 2017), estimating a negative elasticity implies a larger multiplier. Second, we find that exogenous changes in defense spending produce smaller total government spending multipliers than exogenous changes in total government spending. Third, accounting for the heteroskedasticity in US macroeconomic data implies an efficient weighting of observations. The generalized model puts more weight on observations with low error variance compared to observations with high error variance, producing a different estimate than linear models with constant variance and weighting over time.

In the second part of the paper, we exploit that the Markov switching model naturally lends itself to an evaluation of the state-dependent effects of government spending shocks. We show that the multiplier is considerably smaller in the high volatility regime than in the low volatility regime. This finding is consistent with an increased option value of waiting, or region of inaction, that reduces the effectiveness of fiscal stimulus in these periods. It supports theoretical predictions of models that imply lower general equilibrium effects of macroeconomic policy when the time-varying second moments of structural shocks increase (Bernanke, 1983, Bloom et al., 2018). Typically, such an increase is interpreted as ex ante uncertainty of about the future state of the economy (Basu and Bundick, 
2017). Overall, our state-dependent findings highlight the important role of uncertainty in shaping the fiscal policy transmission mechanism.

\section{References}

Alloza, Mario (2017). "Is fiscal policy more effective in uncertain times or during recessions?" Tech. rep. Banco de Espana.

Auerbach, Alan J. and Yuriy Gorodnichenko (2012). "Measuring the Output Responses to Fiscal Policy". American Economic Journal: Economic Policy 4, 1-27.

Bacchiocchi, Emanuele and Luca Fanelli (2015). "Identification in Structural Vector Autoregressive Models with Structural Changes, with an Application to US Monetary Policy". Oxford Bulletin of Economics and Statistics 77, 761-779.

Barro, Robert J. and Charles J. Redlick (2011). "Macroeconomic Effects From Government Purchases and Taxes". The Quarterly Journal of Economics 126 (1), 51-102.

Basu, Susanto and Brent Bundick (2017). "Uncertainty Shocks in a Model of Effective Demand". Econometrica 85, 937-958.

Ben Zeev, Nadav and Evi Pappa (2017). "Chronicle of a War Foretold: The Macroeconomic Effects of Anticipated Defence Spending Shocks". The Economic Journal 127, 1568-1597.

Bernanke, Ben (1983). "Irreversibility, Uncertainty, and Cyclical Investment". The Quarterly Journal of Economics 98, 85-106.

Bertolotti, Fabio and Massimiliano Marcellino (2017). "Tax shocks with high and low uncertainty". Tech. rep. CEPR Discussion Papers.

Bilbiie, Florin, Andre Meier, and Gernot J. Müller (2008). "What Accounts for the Changes in U.S. Fiscal Policy Transmission?" Journal of Money, Credit and Banking 40, 1439-1470.

Blanchard, Olivier and Roberto Perotti (2002). "An Empirical Characterization of the Dynamic Effects of Changes in Government Spending and Taxes on Output". The Quarterly Journal of Economics 117 (4), 1329-1368.

Bloom, Nicholas (2009). "The impact of uncertainty shocks". Econometrica 77 (3), 623685.

Bloom, Nicholas, Max Floetotto, Nir Jaimovich, Itay Saporta Eksten, and Stephen J. Terry (2018). "Really Uncertain Business Cycles". Econometrica 86, 1031-1065.

Bouakez, Hafedh, Foued Chihi, and Michel Normandin (2014). "Measuring the effects of fiscal policy". Journal of Economic Dynamics and Control 47, 123-151.

Caldara, Dario and Christophe Kamps (2017). "The Analytics of SVARs: A Unified Framework to Measure Fiscal Multipliers". The Review of Economic Studies 84 (3), 1015-1040.

Canova, Fabio and Evi Pappa (2011). "Fiscal policy, pricing frictions and monetary accommodation". Economic Policy 26 (68), 555-598.

Carriero, Andrea, Todd E Clark, and Massimiliano Marcellino (2016). "Common drifting volatility in large Bayesian VARs". Journal of Business 8 Economic Statistics 34 (3), 375-390. 
Chodorow-Reich, Gabriel (2019). "Geographic Cross-Sectional Fiscal Spending Multipliers: What Have We Learned?" American Economic Journal: Economic Policy 11 (2), $1-34$.

Christiano, Lawrence, Martin Eichenbaum, and Sergio Rebelo (2011). "When Is the Government Spending Multiplier Large?" Journal of Political Economy 119, 78-121.

Christiano, Lawrence J, Martin Eichenbaum, and Charles L Evans (1999). "Monetary policy shocks: What have we learned and to what end?" Handbook of Macroeconomics $1,65-148$.

Davig, Troy and Eric M. Leeper (2011). "Monetary-fiscal policy interactions and fiscal stimulus". European Economic Review 55 (2), 211-227.

Diebold, Francis X., Frank Schorfheide, and Minchul Shin (2017). "Real-time forecast evaluation of DSGE models with stochastic volatility". Journal of Econometrics 201, $322-332$.

Fernandez-Villaverde, Jesus, Pablo Guerron-Quintana, Juan F. Rubio-Ramirez, and Martin Uribe (2011). "Risk Matters: The Real Effects of Volatility Shocks". The American Economic Review 101, 2530-2561.

Forni, Lorenzo, Libero Monteforte, and Luca Sessa (2009). "The general equilibrium effects of fiscal policy: Estimates for the euro area". Journal of Public Economics 93 (3-4), $559-585$.

Gali, Jordi, J. David Lopez-Salido, and Javier Valles (2007). "Understanding the Effects of Government Spending on consumption". Journal of the European Economic Association 5, 227-270.

Hall, Robert E. (2009). "By How Much Does GDP Rise If the Government Buys More Output?" Brookings Papers on Economic Activity 40, 183-249.

Hansen, Bruce E (1992). "The likelihood ratio test under nonstandard conditions: testing the Markov switching model of GNP". Journal of Applied Econometrics 7 (S1).

Herwartz, Helmut and Helmut Lütkepohl (2014). "Structural Vector Autoregressions with Markov Switching: Combining Conventional with Statistical Identification of Shocks". Journal of Econometrics 183 (1), 104-116.

Justiniano, Alejandro and Giorgio E Primiceri (2008). "The time-varying volatility of macroeconomic fluctuations". American Economic Review 98 (3), 604-41.

Lanne, Markku, Helmut Lütkepohl, and Katarzyna Maciejowska (2010). "Structural vector autoregressions with Markov switching". Journal of Economic Dynamics and Control 34 (2), 121-131.

Leeper, Eric M., Todd B. Walker, and Shu Susan Yang (2013). "Fiscal Foresight and Information Flows". Econometrica 81 (3), 1115-1145.

Leeper, Eric M., Nora Traum, and Todd B. Walker (2017). "Clearing Up the Fiscal Multiplier Morass". American Economic Review 10\%, 2409-54.

Lewis, Daniel (2019). "Identifying shocks via time-varying volatility". FRB of New York Staff Report (871).

Lütkepohl, H. and T. Schlaak (2018). "Choosing between different time-varying volatility models for structural vector autoregressive analysis". Oxford Bulletin of Economics and Statistics 80 (4), 715-735. 
Lütkepohl, Helmut, Mika Meitz, Aleksei Netšunajev, and Pentti Saikkonen (2018). "Testing identification via heteroskedasticity in structural vector autoregressive models". Tech. rep. DIW Discussion Paper No. 1764.

McDonald, Robert and Daniel Siegel (1986). "The Value of Waiting to Invest". The Quarterly Journal of Economics 101 (4), 707-728.

Miyamoto, Wataru, Thuy Lan Nguyen, and Dmitriy Sergeyev (2018). "Government Spending Multipliers under the Zero Lower Bound: Evidence from Japan". American Economic Journal: Macroeconomics 10, 247-77.

Monacelli, Tommaso, Roberto Perotti, and Antonella Trigari (2010). "Unemployment fiscal multipliers". Journal of Monetary Economics 57 (5), 531-553.

Perotti, Roberto (2005). "Estimating the Effects of Fiscal Policy in OECD Countries". CEPR Discussion Papers 4842.

Psaradakis, Zacharias and Nicola Spagnolo (2006). "Joint determination of the state dimension and autoregressive order for models with Markov regime switching". Journal of Time Series Analysis 27 (5), 753-766.

Ramey, Valerie A. (2011). "Identifying Government Spending Shocks: It's all in the Timing*". The Quarterly Journal of Economics 126, 1-50.

Ramey, Valerie A and Sarah Zubairy (2018). "Government spending multipliers in good times and in bad: evidence from US historical data". Journal of Political Economy 126 (2), 850-901.

Ricco, Giovanni, Giovanni Callegari, and Jacopo Cimadomo (2016). "Signals from the government: Policy disagreement and the transmission of fiscal shocks". Journal of Monetary Economics 82, 107-118.

Rigobon, Roberto (2003). "Identification through heteroskedasticity". The Review of Economics and Statistics 85 (4), 777-792.

Sims, Christopher A and Tao Zha (2006). "Were there regime switches in US monetary policy?" American Economic Review 96 (1), 54-81.

Stock, James H and Mark W Watson (2002). "Has the business cycle changed and why?" NBER macroeconomics annual 17, 159-218.

- (2018). "Identification and estimation of dynamic causal effects in macroeconomics using external instruments". The Economic Journal 128 (610), 917-948.

Tagkalakis, Athanasios (2008). "The effects of fiscal policy on consumption in recessions and expansions". Journal of Public economics 92 (5-6), 1486-1508. 


\section{Appendix}

Figure 13: Multipliers of augmented models including taxes. Notes: The figure shows the point estimates for the dynamic government spending multiplier of augmented models (thin solid lines) and of the underlying three-variable model, which includes taxes instead of the T-Bill rate (thick line), together with $90 \%$ confidence bands for the three-variable model (shaded area).

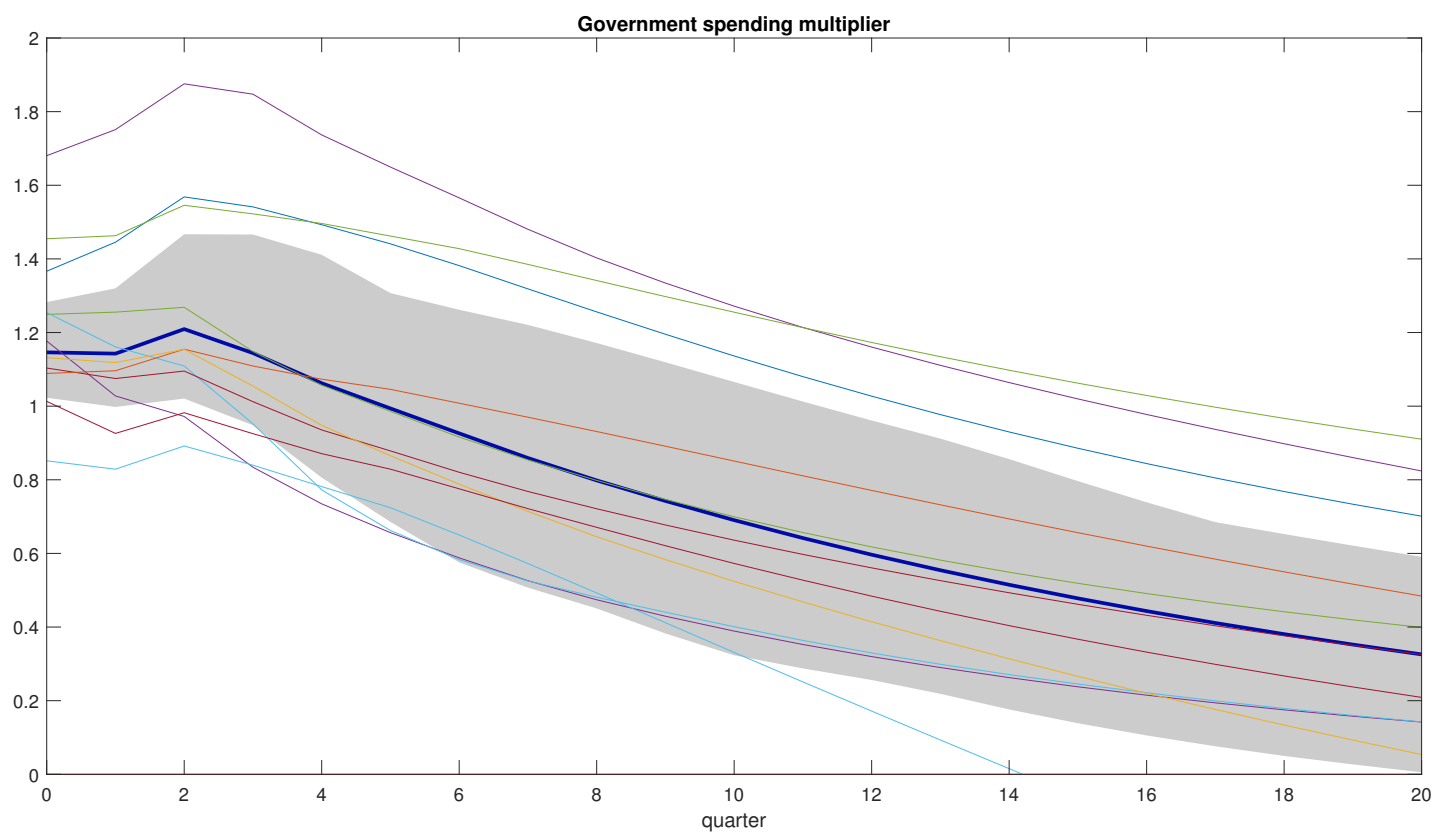

